\title{
Mitochondrial Dysfunction in Parkinson's Disease: Pathogenesis and Neuroprotection
}

\author{
Ross B. Mounsey and Peter Teismann \\ School of Medical Sciences, College of Life Sciences and Medicine, University of Aberdeen, Institute of Medical Sciences, \\ Foresterhill, Aberdeen AB25 2ZD, UK \\ Correspondence should be addressed to Peter Teismann, p.teismann@abdn.ac.uk
}

Received 31 October 2010; Accepted 30 November 2010

Academic Editor: Charleen T. Chu

Copyright ( 92011 R. B. Mounsey and P. Teismann. This is an open access article distributed under the Creative Commons Attribution License, which permits unrestricted use, distribution, and reproduction in any medium, provided the original work is properly cited.

\begin{abstract}
Mitochondria are vitally important organelles involved in an array of functions. The most notable is their prominent role in energy metabolism, where they generate over $90 \%$ of our cellular energy in the form of ATP through oxidative phosphorylation. Mitochondria are involved in various other processes including the regulation of calcium homeostasis and stress response. Mitochondrial complex I impairment and subsequent oxidative stress have been identified as modulators of cell death in experimental models of Parkinson's disease (PD). Identification of specific genes which are involved in the rare familial forms of PD has further augmented the understanding and elevated the role mitochondrial dysfunction is thought to have in disease pathogenesis. This paper provides a review of the role mitochondria may play in idiopathic PD through the study of experimental models and how genetic mutations influence mitochondrial activity. Recent attempts at providing neuroprotection by targeting mitochondria are described and their progress assessed.
\end{abstract}

\section{Introduction}

Parkinson's disease (PD) is a chronic, progressive neurodegenerative disorder, the second most common age-related neurodegenerative disease after Alzheimer's disease [1]. It can be characterised clinically by rigidity, resting tremor, and postural instability [2]. These symptoms result from the loss of dopaminergic neurons in the substantia nigra pars compacta (SNpc) and a subsequent depletion of dopamine in the striatum [2].

The etiopathogenesis of PD is still not fully understood. 95\% of cases are sporadic: a multifactorial, idiopathic disorder resulting from contributions of environmental and genetic susceptibility. The remaining $5 \%$ is the result of genetic mutations, of which there are several types, many only recently identified. However, old age remains the greatest risk factor, with $0.3 \%$ of the entire population affected, rising to more than $1 \%$ in the over $60 \mathrm{~s}$ and $4 \%$ in those over the age of 80 [3]. The two forms of PD share pathological, biochemical, and clinical features, with dysfunction of mitochondria and associated molecular pathways representing a bridge between the two forms of PD as well as the natural ageing process.

Most mitochondrial dysfunction results from damage to complex I-or NADH (nicotinamide adenine dinucleotide phosphate):ubiquinone oxidoreductase-the first and most complex protein in the electron transport chain [4]. It is a large protein, consisting of 42 or 43 subunits [5] on the inner mitochondrial membrane, which forms part of the oxidative phosphorylation system [6]. Defects to complex I are thought to be central to the pathogenesis of $\mathrm{PD}$, and many other known cell death pathways play a role in complex Imediated dopaminergic cell death, such as Bax transcription activation [7]. Moreover, the presence of intramitochondrial enzymes such as cytochrome $c$ and their role in apoptosis [8] may make mitochondria particularly vulnerable to pathogenic events when physiological mechanisms become disrupted. Oxidative stress can increase the releasable pool of cytosolic cytochrome $c$ [9] - a crucial initiator of the caspase apoptotic signalling cascade [10] — through peroxidation of cardiolipin [7], a mitochondrial-specific lipid. Defects in complex I lower the threshold for Bax-mediated 
mitochondrial-dependent apoptosis [9], a crucial event in the degeneration of dopaminergic neurons in the SNpc [11]. This advances the suggestion that mitochondrial dysfunction is a common link and a point of convergence to different pathogenic pathways.

Mitochondrial dysfunction is implicated further in sporadic PD by the finding that complex I inhibition can decrease proteosomal activity, which in turn renders dopaminergic neurons more susceptible to damage by some neurotoxins [12]. This suggests that a decline in proteasomal activity could be the mechanism by which the ubiquitinproteasomal system is impaired, leading to the development of pathological protein aggregates.

The implication of mitochondrial dysfunction in $\mathrm{PD}$ began with the accidental exposure of 4 Californian drug users to 1-methyl-4-phenyl-1,2,3,6-tetrahydopyridine (MPTP) (see [13] for a summary of the discovery). Their intravenous administration of the meperidine analogue resulted in selective death of cells in the substantia nigra [14]. The toxin has now been extensively used in mice and nonhuman primates as an experimental model for PD [1], which has allowed the molecular basis of neuronal death to be followed. The effect is systemic, with human platelets also vulnerable to $\mathrm{MPP}^{+}$-induced toxicity [15]. The unravelling of the action of MPTP has led to a great deal of information regarding the involvement of mitochondrial dysfunction. Armed with further information regarding the molecular pathogenesis of $\mathrm{PD}$, investigators have identified further toxins with the capacity to be used for PD experimental models [16]. All have mitochondrial dysfunction and the related activation of cellular pathways at the heart of their effects.

\section{Mitochondrial Dysfunction in PD and Oxidative Stress}

Oxidants, including hydrogen peroxide and superoxide radicals, are produced as byproducts of oxidative phosphorylation, making mitochondria the main site of ROS generation within the cell. This is a normal situation and basal levels of ROS can be limited by a range of antioxidants. However, in pathological situations, where mitochondrial respiratory defects occur, the amount of ROS produced by the electron transport chain increases dramatically, swamping the antioxidant protection mechanisms. PD has been shown to produce these conditions. A postmortem description of complex I deficiency in the substantia nigra of PD patients led to the direct link between mitochondrial dysfunction and the disease [17], which has since been repeatedly observed [18]. Respiratory chain defects can also be found in platelets [19] and other highly oxidative tissues, such as skeletal muscle [20], in idiopathic PD.

Perier et al. [9] has linked increased ROS levels to complex I inhibition with the use of neurotoxin models. Complex I defects can lower the threshold of apoptosis mediated by mitochondria through depletion in ATP production and the generation of free radicals [9]. Elevated ROS levels can also result in damage to phospholipids and polyunsaturated free fatty acids (PUFA), which are both highly prevalent in the brain and very susceptible to oxidative damage. In PD, lipid peroxidation is increased in the SN up to the time of death compared to age-matched controls, as shown by lower PUFA content-an index of the amount of available substrate available for lipid peroxidation-in post-mortem tissue [21]. Levels of markers of oxidative damage to proteins are also increased in $\mathrm{PD}$ post-mortem tissues, with a twofold increase in the SN $[22,23]$. Two reasons are given for this region-specific protein carbonyl rise: the symptomatic PD treatment levodopa contributes to this oxidation [22], and oxidative damage is higher in dopaminergic neurons [23]. Studies have sought to find if this oxidation, and subsequent disease progress, is related to excess production of ROS or inadequate and impaired detoxification by the endogenous antioxidants. Analysis of superoxide dismutase (SOD) levels show no change in SOD1 (cytosolic isoform) levels, but there is an increase in activity of the inducible mitochondrial isoform SOD2 [24]. This suggests that mitochondria are the location of increased ROS production and are the site of the first line of defence against oxidative stress.

\section{Experimental Models and Mitochondrial Dysfunction}

The discovery by Langston and colleagues in 1983 that the neurotoxin MPTP causes specific and irreversible damage to dopaminergic neurons and generates Parkinsonian symptoms [14] caused a surge in activity in PD research. The use of a reproducible model allowed for the pathogenic events to be studied, which has led to the gradual unravelling of many of the biochemical disturbances (although some steps remain unknown). Several other compounds induce dopaminergic cell death, with all affecting mitochondrial physiology.

3.1. MPTP. The metabolism of MPTP occurs in a complex and stepwise fashion [25]. As it is highly lipophilic, the compound can rapidly (within seconds) cross the bloodbrain barrier (BBB) after systemic administration. The protoxin MPTP is metabolised within the brain to the unstable molecule 1-methyl-4-phenyl-2,3-dihydropyridinium (MP$\mathrm{DP}^{+}$) by monoamine oxidase (MAO), specifically the MAO$B$ subtype enzyme within nondopaminergic neurons due to the cellular localisation of the enzyme [26]. Then, probably due to spontaneous oxidation, it forms the active toxin 1-methyl-4-phenylpyridinium $\left(\mathrm{MPP}^{+}\right)$[27]. $\mathrm{MPP}^{+}$is then released via an unknown mechanism into the extracellular space. It is the next step which accounts for the selectivity of the toxin: as $\mathrm{MPP}^{+}$is a polar molecule it cannot freely enter cells, unlike its precursor, MPTP. The toxin does however have a high affinity for plasma membrane dopamine transporter (DAT), as the use of DAT inhibitors $[28,29]$ or the absence of DATs [30] prevent its uptake. Once inside dopaminergic neurons, there are at least three routes which $\mathrm{MPP}^{+}$can take [31]: it can take the vesicular pathway, bind to vesicular monoamine transporters and translocate $\mathrm{MPP}^{+}$ into synaptosomal vesicles [32]; it can interact with various cytosolic enzymes by remaining in the cytosol [33], or can be concentrated within the mitochondria [34]. The effect of the latter of these three routes will now be discussed. However, 
it should be noted that a cascade of deleterious effects [31] contribute to a greater or lesser extent to dopaminergic cell death, and no factor alone is the sole cause of the degeneration.

$\mathrm{MPP}^{+}$enters the mitochondria passively due to the large transmembrane potential of mitochondrial membranes and accumulates at the matrix. The levels of $\mathrm{MPP}^{+}$in the mitochondria can reach saturation within a few minutes [34]. The rate of the toxin's uptake depends on its intramitochondrial concentration, which inversely affects the transmembrane potential [34]. This equilibrium is disrupted when mitochondria become anaerobic or the transmembrane potential gradient is disturbed by the presence of an uncoupling agent [34].

Once $\mathrm{MPP}^{+}$has entered the mitochondria in this potent and rapid manner, the toxin can affect various functional elements of the organelles. For example, the tricarboxylic acid cycle enzyme $\alpha$-ketoglutarate dehydrogenase is inhibited by $\mathrm{MPP}^{+}$[35]. But the main cause of mitochondrial dysfunction involves the compound's action on complex I of the respiratory chain. $\mathrm{MPP}^{+}$binds to complex I soon after its uptake by dopaminergic neurons. Rotenone (discussed below) is a classic complex I inhibitor. Its binding is blocked by the presence of $\mathrm{MPP}^{+}$[36], confirming the site of the toxin's action. It has been found that the binding of $\mathrm{MPP}^{+}$ is required at two distinct sites (one hydrophilic and one hydrophobic) for complete NADH inhibition, but it provides a much weaker inhibition of complex I than rotenone $[4,37]$. The binding to the first of these sites affects the coupling between the PSST and NADH dehydrogenase (ND) 1 subunits (20 and $36 \mathrm{kD}$, resp.) of complex I, while the location of the second site, although apparently causing a more potent a more potent inhibition of complex I enzymatic activity [4], is not precisely known. The flow of electrons is interrupted in a dose- and time-dependent manner, leading to an acute deficit in ATP production, particularly in the striatum and ventral midbrain $[38,39]$. However, due to the low levels (around 20\%) of ATP depletion which actually occurs in vivo in whole mice brain tissues [38] and the evidence that there is little or no neuronal loss when residual ATP levels are maintained above $20 \%$ [11], there is thought to be more prominent factors causing MPTP-induced dopaminergic cell death than a $\mathrm{MPP}^{+}$-related reduction in ATP levels. In addition to this, complex I activity is required to be reduced by more than $50 \%$ to cause significant ATP depletion [40]. The role of complex I inhibition in $\mathrm{MPP}^{+}$toxicity is further questioned by Choi et al. [41], who found the toxin caused dopaminergic cell death occurred despite a lack of the $N d u f_{s} 4$ gene, essential for complex I assembly and function. The importance of $\mathrm{MPP}^{+}$binding can be supported, however, by improvements in ATP production and alleviation of degeneration after efforts to stimulate mitochondrial respiration by way of a bypassing of the complex I blockade [42].

Mitochondria are a major source of ROS, with up to $2 \%$ of all oxygen consumed by mitochondria being converted to superoxide [43]. The production of ROS is increased after $\mathrm{MPP}^{+}$inhibition of complex I [32] by more than $40 \%$ over control levels [11], which works in parallel with other reactive molecules including nitric oxide, a molecule produced by the nitric oxide synthase enzyme in the brain [44]. Transgenic mice with increased brain activity of the scavenging enzyme SOD showed resistance to $\mathrm{MPP}^{+}$toxicity [45]. This protective effect did not affect the block on complex I activity, showing the importance and potency of free radical damage in the MPTP model. This enzyme has been localised in the intramembrane space where it acts as a physiological protective mechanism against superoxide toxicity [46]. The deleterious impact of ROS in the MPTP model mirrors the results of studies conducted on human post-mortem samples [47]. It is likely that a depletion of ATP and increased ROS production, following complex I impairment, trigger molecular cell death pathways such the activation of procell death protein Bax [7], and it is these ROS-initiated pathways, rather than an acute energy shortage, which result in the greatest proportion of MPTPinduced degeneration.

It has been proposed that MPTP may also cause dopaminergic cell death through a reduction in the number of lysosomes [48], cytoplasmic organelles containing hydrolytic enzymes important in the degradation of cytoplasmic proteins, and other organelles through the process of macrophagy [49] (also see mitophagy, which is discussed in Section 5.3). ROS, levels of which are elevated due to mitochondrial dysfunction, cause permeabilisation of lysosomes leading to defective clearance and accumulation of the double-bonded sequesters of the cytosolic material to be degraded, autophagosomes (APs). Lysosomal depletion and neurodegeneration subsequently occur after ectopic release of lysosomal proteases. Induction of lysosomal biogenesis attenuated the MPTP-induced cell death [48], while rapamycin, an inhibitor of the cellular kinase mammalian target of rapamycin (mTOR) known to induce autophagy, can restore lysosomal levels and reduce AP accumulation $[48,50]$. This represents a further pathway by which ROS released in energy-deprived cells cause cell death in this model.

3.2. Rotenone. Rotenone is used commonly as a pesticide in the UK and United States. Its use in South America dates back to the 17th century as an agent to paralyse and surface fish. Epidemiological studies have established a link between contact with pesticides and an increased risk of Parkinson's [51], although the short half-life of the compound, particularly in sunlight (1-3 days), and the fact that it does not leach from soils mean the chance of PD being caused directly from environmental exposure to this pesticide is very low, with others leading to the aforementioned epidemiological trend [52]. Rotenone is a specific inhibitor of complex I and causes its deleterious effects through oxidative damage, with only mild depletion of ATP levels [53]. This toxicity can be prevented with the administration of antioxidants [53]. Rotenone rapidly crosses the BBB thanks to its lipophilic structure, with maximal CNS concentrations reached within just 15 minutes [54]. Within cells, rotenone freely crosses into subcellular compartments including mitochondria, in which the toxin impairs oxidative phosphorylation by binding to the PSST subunit of complex I [4]. Interestingly, 
due to this promiscuous manner of cell entry, rotenone does not concentrate within dopaminergic cells selectively, unlike MPTP, although cell death is specific to these cells. Therefore, dopamine cells appear to be particularly sensitive to the resultant complex I dysfunction [55]. Again unlike MPTP, rotenone leads to the presence of Lewy bodies [56], the proteinaceous pathologic biomarker of sporadic PD. These inclusions are immunoreactive to $\alpha$-synuclein and ubiquitin [56]. The evidence that rotenone, a classic complex I inhibitor, causes aggregation of Lewy bodies may mean that mitochondrial dysfunction has a role in the development of these pathologic protein inclusions in PD [57]. Furthermore, recent evidence shows that rapamycin protects against rotenone-induced apoptosis by the induction of autophagy in SH-SY5Y human neuroblastoma cells [58]. This provides a further link between mitochondrial dysfunction and the toxic effect of rotenone, with the clearance of the impaired organelles induced by rapamycin preventing increases in cytochrome $c$ levels and apoptotic pathways [58].

3.3. 6-OHDA. 6-hydroxydopamine (6-OHDA) is a hydroxylated analogue of dopamine, first isolated in 1959 [59]. It has been used most extensively in rodents. By virtue of its structure, 6-OHDA possesses a high affinity for many catecholamine membrane transporters including DAT and norepinephrine transporters, allowing the compound to freely enter both dopaminergic and noradrenergic neurons [16]. This leads to a lack of specificity, as damage can be caused centrally and peripherally to these signalling pathways. Therefore, administration needs to be precise: stereotaxic injection is usually the route used to create a Parkinsonian lesion (6-OHDA does not cross the BBB well spontaneously, thus systemic administration does not result in the accumulation of neurotoxic concentrations), which represents a technical challenge. Once in catecholamine cells, 6-OHDA causes damage through reactive oxygen species and quinones [60]. The fine molecular details of neuronal death are more difficult to understand with this model, however, as the ways by which cytotoxic events occur may differ depending upon the distance between them and the site of injection [16]. Despite this, some of these details have begun to be uncovered, including the induction of autophagy through activation of extracellular signal-regulated kinase (ERK) $1 / 2$ [61, 62]. Inhibition of the ERK pathway confers neuroprotection in 6-OHDAtreated cells [62]. The mitochondrial localisation of ERK2 in particular causes enhanced autophagy to levels which cause a pathologic reduction in ATP production due to the degradation of healthy mitochondria [61], providing a molecular component in 6-OHDA cytotoxicity.

\section{Mitochondrial DNA}

An extra level of complexity is added to mitochondria as they can house their own mitochondrial DNA (mtDNA), possibly due to an ancestry to free-living bacteria that became trapped to form eukaryotic cells [63]. This confers an extent of genomic autonomy to these organelles, but given their precarious yet vital position and specific vulnerability to toxins, it may increase the likelihood of pathogenic alterations occurring. Mitochondrial DNA is prone to point mutations at a higher frequency than DNA in other parts of the genome. This is due to a lack of repair mechanism, small mitochondrial genome size (around $16 \mathrm{~kb}$ in length), and the close proximity of the genome to the site of ROS production at the inner mitochondrial membrane. Consequently, an accumulation of mtDNA mutations occurs throughout life and results in precipitation of pathological disorders due to a gradual degradation of mitochondrial efficiency [64-66]. As PD development is intrinsically linked with age, this is an attractive hypothesis to couple with what is known about the disorder's pathogenesis. There have been various reports to back this up $[67,68]$, although no single gene defect appears likely to cause more damage than others, with gene mutations combining in a complex manner [69]. However, the role of mitochondrial point mutations in ageing has been questioned by Vermulst et al. [70], who found that mutation frequency was 11-times lower than previously reported [71] and did not have an effect on ageing in wild-type mice. The group also debated the validity of previous data on the basis of the PCR and cloning strategies used, techniques that are limited by polymerase infidelity and cloning artefacts. In another contradiction to the link between mtDNA defects and age, a higher rate of homoplasmic mtDNA mutations has been found in PD patients from younger subjects, who have had less significant SN dopaminergic loss (M.F. Beal, unpublished findings, cited in Banerjee et al. [72]). Thus, the correlation between mtDNA damage, age, and PD incidence is by no means indivisible.

Most neuropathological studies have been limited to skeletal muscle, which provides an accessible tissue, important in the diagnosis of mtDNA disorders and often involves functional muscle impairment. Muscle from these patients has been found to feature respiratory chain-deficient muscle fibres. These particular fibres showed higher levels of mtDNA deletion than normal fibres. Muscle specific mtDNA mutations were found in this postmitotic tissue, demonstrating the propensity mtDNA has to mutate and for these point mutations to accumulate [73]. Mitochondrial proliferation is linked to apoptosis and a high amount of mutations [74].

It has been found that complex I defects (a 25\% deficiency was shown) from PD patients can be transferred into mitochondrial deficient platelet cybrids [75]. These defects can affect calcium homeostasis by altering mitochondrial membrane potential, an elevation of ROS production and reduced ATP production [76]. Since mtDNA encodes 7 of the 49 protein subunits of the complex I enzyme, it is fair to surmise that any defects to this genomic structure would have palpable functional disturbances.

The SN may be particularly susceptible to the accumulation with age of somatic mtDNA mutations due to their age-related loss, high oxidative capacity, and sensitivity to mitochondrial dysfunction [77]. Indeed, this group show high levels of mtDNA deletions associated with decreased cytochrome oxidase activity in SN neurons of both aged and PD patients and demonstrated mitochondrial respiratory chain impairment. Mitochondrial DNA deletions of over $43 \%$ and $52 \%$ of total mtDNA in individuals over the age 
of 70 and in PD patients, respectively, were found [77]. This data, combined with that of the independent study carried out by Kraytsberg et al. [71] show that parkinsonism enhances the impairments already suffered by aged SN neurons due to mtDNA damage. However, despite this correlation, it is not clear whether mtDNA mutations are the primary cause of mitochondrial dysfunction or exist secondary to the organelle's functional impairment. Reeve et al. [78] outlines the hypothesis that somatic mtDNA mutations occur as a result of oxidative stress and clonally expand. Cells affected by PD (i.e., neurons in the SN) are more likely to contain mtDNA mutations due to the stresses that these cells are subject to. This provides a composite conclusion of both schools of thought, whereby mtDNA mutations are originally secondary to the primary cause of disease and/or cellular stress, but once clonally expanded can contribute to the pathogenesis of the disease by participating in cell death pathways.

Outside of a role in conferring functional deficits, human mtDNA exhibits region-specific variation in indigenous populations, allowing these haplogroups to be phylogenetically organised. Geographical-dependent replacement mutations and amino acid conservation substitutions have allowed our ancestors to survive more northern climates and higher altitudes [79]. This has consequences in health today, with some mtDNA haplotypes influencing PD expression. Van der Walt et al. [80] found a single-nucleotide polymorphism at $10398 \mathrm{G}$ in individuals classed as haplogroup J, which confers neuroprotection, particularly in women. The haplotype causes an amino acid change from threonine to alanine in the ND3 subunit of complex I [80]. A disease-specific link with the mtDNA cluster UKJT has also been found and is reported to cause a $22 \%$ reduction in population-attributable risk for PD [81]. In a study of a Finnish population, an excess of nonsynonomous substitutions to complex I genes in mtDNA in the JTIWX supercluster increased the risk of PD and PD with dementia by 2.5 -fold. This supports the theory that the total number of substitutions in mtDNA conveys the risk of $\mathrm{PD}$ rather than individual mutations [82].

\section{Genetic Causes of PD and Mitochondria}

Heritable cases of PD make up a very small proportion of PD cases, but a heritable factor may predispose an individual to the development of the disease [83] and are involved in early onset forms of the disorder [84-86]. As discussed so far, mitochondrial dysfunction is central to the pathogenesis of PD, thus it follows that the gene defects outlined here also directly or indirectly affect mitochondrial function.

5.1. $\alpha$-Synuclein. This soluble, acidic, presynaptic nerve terminal protein has an increased tendency to aggregate due to its hydrophobic non- $\beta$-amyloid domain, and forms the major structural component of Lewy bodies, as well as acting as the precursor protein for amyloid plaques in Alzheimer's disease [87]. Physiologically in the substantia nigra, it may have a role in the filling and refilling of synaptic vesicles [88]. Three missense mutations, A53T [89], A30P [90] and E46K [91], and one triplication [92] of this 140-amino acid protein have so far been found to cause an autosomal dominant inherited form of PD. It has been discovered in yeast that functional mitochondrial DNA is essential for $\alpha$-synuclein toxicity [93]. Evidence also suggests a role for $\alpha$-synuclein in causing mitochondrial dysfunction. A study of the A53T transgenic mouse, in which the polymerisation process which ultimately converts monomers into amyloid fibrils is accelerated, established that these mice develop dysmorphic mitochondria in brain stem and spinal cord cells [94]. It has also been found in vitro that overexpression of $\alpha$-synuclein impairs mitochondria structure and function [95]. In addition to this, cytochrome $c$ interacts with mitochondria in Lewy bodies to promote their aggregation [96], as well as activating cell death pathways. Mitochondrial DNA damage was also found in A53T mice, while nuclear DNA remained intact [94], demonstrating the increased vulnerability of mtDNA. Wildtype $\alpha$-synuclein is protective and lowers staurosporineinduced caspase- 3 activity and p53 expression [97], but these effects can be reversed by the addition of 6-OHDA, thus shifting this antiapoptotic protective function to one which contributes to the aggregation of $\alpha$-synuclein [98], suggesting an indirect mechanism by which mitochondria interact with cell death pathways. Mutant $\alpha$-synuclein expression in vitro show reduced proteasomal activity without direct toxicity, although they were more sensitive to apoptoticmediated cell death along with mitochondrial depolarisation and caspase- 3 and -9 elevation when treated with subtoxic concentrations of a proteasomal inhibitor [99], linking the paths of mitochondrial dysfunction and protein aggregation. But it remains unclear whether mitochondrial dysfunction precedes $\alpha$-synuclein inclusion formation or vice versa. They are, however, intrinsically linked. $\alpha$-synuclein associates with mitochondria during pathologic conditions: a sequence in the $\mathrm{N}$-terminal of human protein contains a mitochondrial-targeting signal that leads to $\alpha$-synuclein associating with the inner membrane of the mitochondria, resulting in complex I impairment and increased ROS production [100], increased protein tyrosine nitration and a decreased mitochondrial transmembrane potential [101]. The cell death pathway mediator, cytochrome $c$, is also released upon this aggregation [102]. The association of $\alpha$-synuclein and mitochondria was especially significant in $\mathrm{PD}$-vulnerable brain regions, that is, $\mathrm{SNpc}$ and striatum [100]. Rotenone-induced aggregation of $\alpha$-synuclein, and the subsequent decrease in ATP levels, was reversed by the removal of the complex I inhibitor [103], highlighting the importance of mitochondrial impairment to aggregate formation. The possibility that the combination of $\alpha$-synuclein and mitochondria is a protective measure can be countered by evidence that $\alpha$-synuclein-null mice are resistant to mitochondrial toxins, including MPTP $[104,105]$. It has been suggested that abnormal cytosolic conditions are required for this signalling to become active and translocation to take place: it occurs rapidly in low intracellular $\mathrm{pH}$ [106], a condition which may be caused by ROS overproduction and metabolic stress. Thus, biochemical abnormalities interact with genetic modifications to the $\alpha$-synuclein gene resulting in the impairment of mitochondrial function and 
subsequent neuronal degeneration. These interactions are demonstrated in Figure 1.

5.2. Parkin. Mutations to the parkin gene (PARK2) are linked to an autosomal recessive juvenile form of the disease [107], constituting the most common cause of young onset PD. Hundreds of such cases have been found in patients from almost all ethnic backgrounds [108]. The parkin gene encodes a 465 amino acid RING finger-containing protein. Like other RING finger proteins, parkin acts as a ubiquitin E3 ligase. It has an important role in the function of ubiquitin, which is primarily involved in the targeting of aggregation-prone substrates for degradation by proteosomes, by conferring substrate specificity (parkin's function is reviewed [109]). This function has been shown in vitro [110]. Thus, mutations to parkin may cause loss of this ligase activity resulting in accumulation of toxic substrates and degeneration, with many potential substrates for parkin [109]. The fact that these substrates do not fit into a common pathway may be due to the broad range of regulatory functions, alongside protein aggregate degradation, which ubiquitin fulfils. These include signal transduction, postreplicative DNA repair, endocytosis protein trafficking, and regulation of transcription and translation [111].

But parkin's most reproducible, and possibly most relevant, activity is its neuroprotective activity against a variety of pathogenic factors. At least, some of this neuroprotection is afforded by delaying mitochondrial swelling and rupture and the subsequent cytochrome $c$ release and caspase- 3 activation, as demonstrated in cells overproducing parkin [112]. The importance of parkin in the normal function of mitochondria as a controller of cytochrome $c$ release, and therefore apoptosis, is underlined by the inverse relationship expression levels of parkin share with cytochrome $c$ release [113]. Parkin can become associated with the mitochondria, particularly the outer membrane, suggesting a direct and local protective effect [114]. The protein is involved with the regulation of transcription and replication of mitochondrial DNA in proliferating cells, stimulating the organelle's biogenesis-an effect blocked by parkin short-interfering RNA (siRNA) knockdown [114]. This has been backedup in vivo: parkin-null mice show reduced mitochondrial respiratory capacity as well as increased protein and lipid peroxidation [115] leading to nigrostriatal defects but not loss of dopaminergic neurons [116]. Mitochondrial morphological changes have been observed, but this led only to disruption of complex I function in nigral mitochondria and did not result in cell death [117]. Abnormal morphological branching of mitochondria and lowered complex I-mediated ATP production have been described in parkin-mutant fibroblasts, but these functional impairments did not occur when parkin was knocked down by 50\% [118]. An increased susceptibility to oxygen radical damage has been observed in parkin-null Drosophila [119]. A comprehensive study has confirmed the association between parkin and mtDNA, leading to protection from oxidative stress and stimulation of mitochondrial genome damage [120]. These functions were impaired in parkin-deleted human fibroblasts [120]. Thus, functional parkin is important in the maintenance of mitochondrial antioxidant defences and protection of mtDNA.

5.3. PINK-1. PINK1 (PTEN-induced putative kinase 1) gene mutations are the second most common cause of autosomal recessive, early-onset parkinsonism [86]. This 581 amino acid protein features a serine/threonine kinase domain, which is the site of most missense mutations, leading to impairment of kinase activity [86]. Like parkin, PINK-1 has been shown to be protective in a number of stress paradigms [121-123]. Nigrostriatal neuronal loss has been observed in post-mortem brains of PD patients with PINK1 mutations [124]. This study also showed the localisation of PINK1 to mitochondria. It is here that PINK1 mutations are thought to cause PD by impaired phosphorylation of its substrates, although the precise mitochondrial location of PINK1 association is unclear [125].

Mutations of PINK1 result in a loss of the protein's function, leading to PD. It is in mitochondria that the impaired phosphorylation is most deleterious: mitochondrial cristae are fragmented in PINK1 mutants, and there is increased susceptibility to oxidative stress [126]. PINK1 mutants share many phenotypic characteristics with parkin mutants $[127,128]$. It could then be delineated that the two proteins act in a common pathway, with parkin functioning downstream of PINK1, as transgenic expression of parkin ameliorated all PINK1 impairments, but not vice versa [127129]. Further interplay between these proteins has recently been uncovered (see Figure 2). Recent evidence has suggested that PINK1 along with parkin has a role in the mitochondrial targeting of autophagy, a process by which cells degrade intracellular material via the employment of lysosomes [130]. Mitophagy, the mitochondrial-specific form of the process, is important in the disposal of damaged or stressed organelles. The process is upregulated after disturbances in mitochondrial membrane permeability (reviewed in [131]). Accumulation of mutated $\alpha$-synuclein protein also initiates this compensatory mechanism [132] (although parts of the autophagic-lysomal system may be impaired in these cases, as levels of the lysosomal protease cathepsin D are reduced $[133,134])$. Parkin is selectively recruited from the cytosol to mitochondria with low membrane potential, where the protein mediates the degradation of the dysfunctional organelle (induced in this study using the uncoupler carbonyl cyanide m-chlorophenylhydrazone (CCCP)) by lysosomes [135]. PINK1 acts as the biochemical signal allowing parkin to identify dysfunctional mitochondria, the levels of which are regulated by voltage-dependent proteolysis [136]. The E3 ligase function of parkin, which is constitutively repressed, becomes activated upon PINK1-dependent mitochondrial localisation [137]. Thus, defective mitophagy due to a lack of parkin recruitment to dysfunctional mitochondria by PINK1 causes the accumulation of impaired mitochondria, and a subsequent buildup of ROS and proapoptotic proteins. The importance of this system is furthered by the evidence that VPS41, a protein known to traffic proteins to lysosomes in yeast, is neuroprotective in 6-OHDA and rotenone cellular models by blocking the apoptotic cascade and enhancing protein clearance, although the toxin-induced mitochondrial 


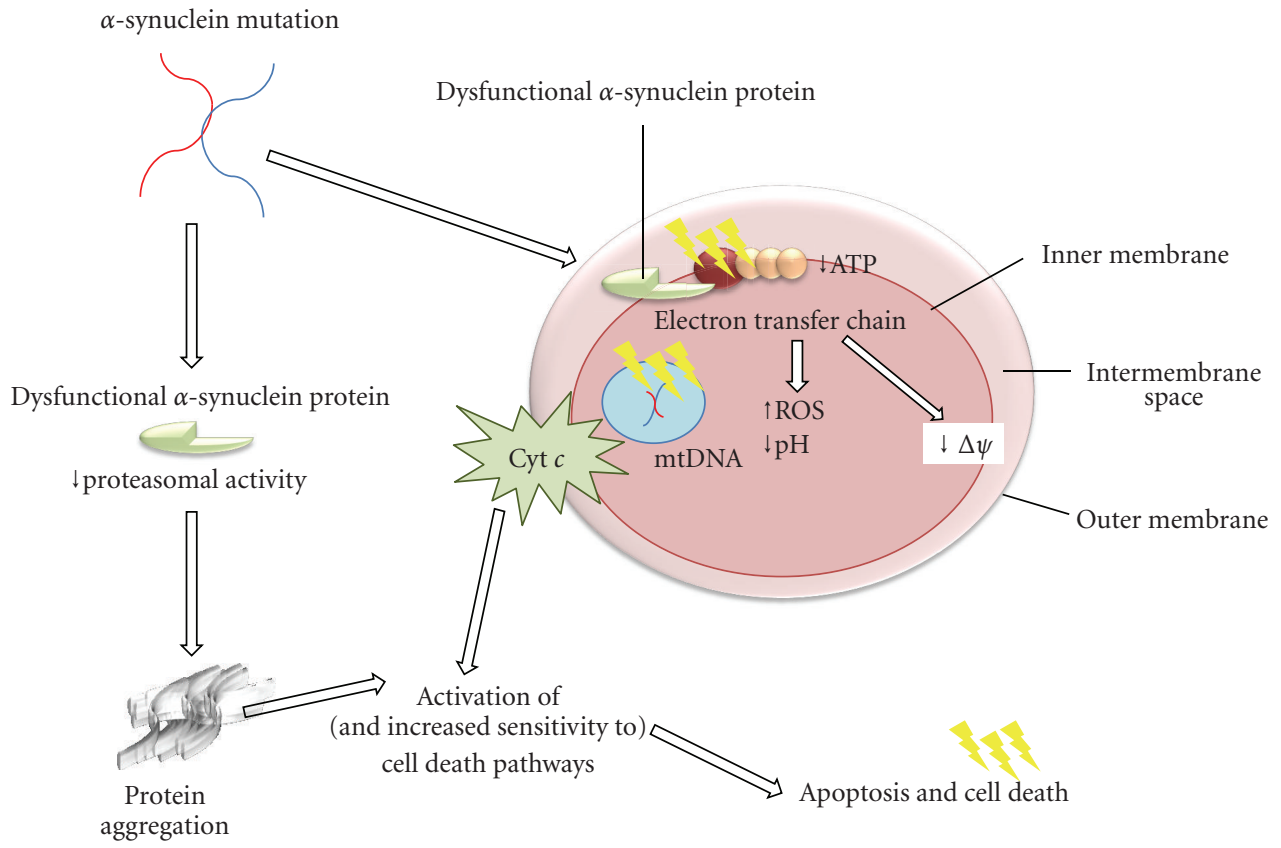

Figure 1: Genetic mutation of $\alpha$-synuclein and subsequent protein and biochemical alterations. Modifications to the $\alpha$-synuclein gene cause dysfunction of its protein product. Proteasomal activity becomes impaired, leading to an increased tendency for the protein to aggregate. Mutated $\alpha$-synuclein protein also localises at the inner mitochondrial membrane, causing complex I dysfunction. ATP production is subsequently reduced, as is the transmembrane potential of the organelle. Increased levels of ROS result, and with mtDNA being particularly susceptible to ROS damage, further cell stress occurs. The acidic cytosolic environment created by ROS and metabolic impairment results in the activation of cell death mediators, such as cytochrome $c$. Apoptotic pathways are initiated and cell death subsequently occurs.

membrane potential disruption was not affected [138]. Vives-Bauza et al. [139] expands upon the functions of parkin and PINK1 by describing a role in mitochondrial trafficking to the perinuclear region-a subcellular area associated with autophagy, again suggesting the proteins function in mitochondrial turnover. These functions are repressed in knockout models of the two proteins involved, implying that a lack of these events play a role in pathogenesis. Moreover, overexpression of parkin enhanced the protective effects of mitophagy, with autophagy proteins such as Atg7 and LC3/Atg8 involved in mitochondria remodelling [140]. This provides a link between morphology and some active processes of mitochondria which impact upon cell survival.

Morphological changes of the tubular networks which mitochondria form impact cell survival, with a balance between the processes of fission and fusion required to maintain morphological integrity. Mitochondria are highly dynamic organelles, and these processes are ongoing. It has been found that overexpression of PINK1 promotes mitochondrial fission while inhibition of the protein causes excessive fusion [141, 142]. The PINK1/parkin pathway thus achieves its effect of mitochondrial integrity by promoting fission [142, 143]. Ageing affects mitochondrial activity and how it reacts to a lack of PINK1: at 3-4 months, impaired mitochondrial function after PINK1 knockout was observed in the striatum but not in the cerebral cortex; however, at 2 years of age, this impairment also occurred in the cortex [144]. Impairments to mitochondrial respiration in this study were induced by cellular stress-mediators, as well as a reduction in the activity of the Kreb's cycle enzyme aconitase, underlining the protein's protective role in mitochondria to intrinsic and extrinsic factors. Examination of fibroblasts from a patient affected by a PINK1 mutation has revealed low mitochondrial respiratory activity and enhanced oxygen radical production due to complex I inhibition [145], demonstrating clinically the effects found experimentally.

5.4. DJ-1. A rarer cause of early-onset forms of $\mathrm{PD}$ is mutations to the gene encoding the 189 -amino acid protein, DJ-1. Affecting the PARK7 gene, they account for $1-2 \%$ of these cases [85]. As with the other proteins outlined, mutant studies demonstrate an increased susceptibility to cell death. Knockdown of DJ-1 by siRNA led to populations of the human neuroblastoma cell line SH-SY5Y becoming susceptible to several oxidative insults including hydrogen peroxide, $\mathrm{MPP}^{+}$and 6-OHDA [146]. Conversely, DJ-1 overexpression in this cell line leads to increased resistance to these insults and reduced intracellular ROS levels [147]. This protection is apparently selective against environmental oxidative stress in vivo, as shown in the paraquat-treated DJ1-null Drosophila model [148]. Furthermore, the levels of DJ-1 modification increase with age, leading to significant increases in oxidative stress and inactivation of the protein's function [149]. This shows that DJ-1 modifications may have a role in sporadic PD in aged animals, in addition to familial early-onset cases. DJ-1-deficient mice show hypersensitivity to MPTP-manifested by increased dopaminergic neuronal loss and striatal denervation [150]. Embryonic cortical 


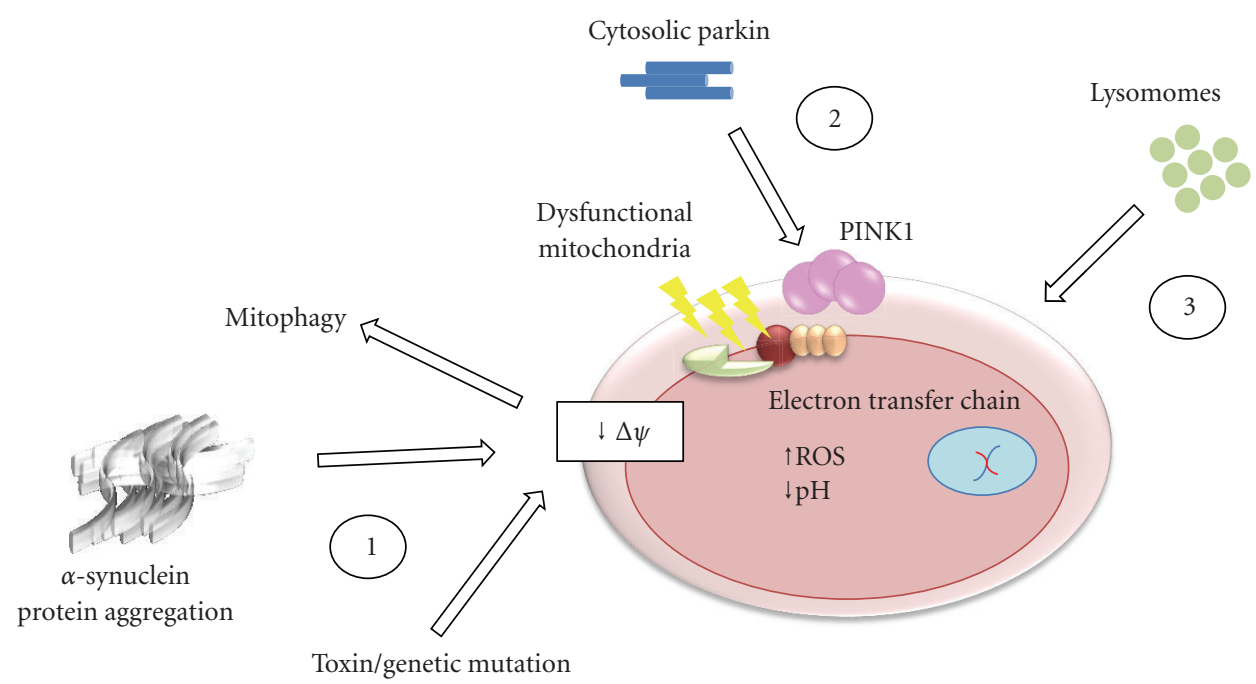

FIGURE 2: The physiological association of parkin and PINK1 proteins in mitophagy. (1) Genetic mutations or the introduction of toxins lead to various impairments, including depletion of ATP production at the electron transfer chain. A buildup of ROS leads to a more acidic environment within the mitochondrion, as well as inducing a decrease in the mitochondrial transmembrane potential after the opening of permeability transition pores. This is the signal for mitophagy to occur. (2) The process is induced through the interaction of cytosolic parkin with mitochondria-associated PINK1. PINK1 acts as the biochemical signal for parkin to identify damaged mitochondria. (3) Parkin then mediates the lysosomal degradation of the dysfunctional organelle.

neurons have shown increased sensitivity to oxidative stress [150] and proteasomal inhibition leading to apoptosis [151]. All impairments were reversed by restoration of DJ-1 expression [150]. DJ-1 is activated by an oxidative cytoplasmic environment [152], thus its protective mechanism works in an on-demand manner. This group describe a role for DJ-1 as a redox-sensitive molecular chaperone, which inhibits $\alpha$-synuclein aggregate formation. The complex I inhibitor paraquat decreased proteasome activity along with ATP and regulatory subunit levels in DJ-1 deficient mice, but not wild-type littermates [153]. In addition to this, a transcription factor, expression nuclear factor erythroid 2related factor 2 (Nrf2), which induces cytoprotective genes, was reduced. This provides evidence that DJ-1 acts as a regulator of transcription. The mechanism by which DJ1 protects against oxidative stress has been investigated: the protein has been shown to regulate the MAP3 kinase apoptosis signalling-regulating kinase 1 (ASK1)/thioredoxin 1 (Trx1) complex [154]. ASK1 is a major effector of oxidative cell death and is physiologically inhibited by Trx1. The association is disrupted by oxidative stimuli, and DJ-1-null cells are more susceptible to this dissociation, leading to increased activation of downstream cell death mediators. It has been shown that DJ-1 does not take part in the PINK1/parkin pathway, as overexpression of DJ-1 could not reverse the PINK1 inactivation phenotype [128].

A direct mitochondrial-DJ-1 association has been uncovered. Lev et al. [147] described a cellular redistribution of DJ1 when cells were exposed to neurotoxins. This is expanded upon by Hayashi et al. [155] who show DJ-1 binding to NADH dehydrogenase (ubiquinone) $1 \alpha$-subcomplex 4 (NDUFA4) and ND1, nuclear and mitochondrial DNAencoding subunits of complex I, demonstrating the importance of DJ-1 in mitochondrial activity. Mitochondrial DJ-1 acts as an atypical peroxiredoxin-like peroxidise, as indicated by the twofold increase in mitochondrial hydrogen peroxide levels in DJ-1 knock-out mice. Cysteine-106 forms the site of the oxidation required for scavenging hydrogen peroxide [156], and potentially other ROS.

5.5. LRRK2. Mutations to the leucine-rich repeat kinase 2 (LRRK2) gene cause a form of autosomal dominant PD. The mutations are associated with familial late-onset PD as well as some sporadic cases of the disorder, which has increased the interest in this gene [157]. The LRRK2 gene encodes a large 2527 amino acid multidomain protein, the physiological function of which is currently unknown. But there are numerous functional domains associated with the protein, including GTPase [158] and kinase domains [157], implying an array of roles. LRRK2 is present largely in the cytoplasm but also associates with the outer membrane of mitochondria [159, 160], suggesting a role in this organelle. However, the role of LRRK2 in PD pathogenesis is questioned by Andres-Mateos et al. [161], who find a sensitivity to MPTP insult of LRRK2 knock-out mice in line with wild-type mice (in contrast to other established gene defects), as well as normal dopaminergic signalling and cell survival levels. Most of the accumulated evidence suggests that a gain-of-function defect causes PD pathology, with an increase in kinase activity prominent in disease development $[160,162]$. It has been found by Lin et al. [163] that LRRK2 mutations accelerate the progression of neuropathological abnormalities in $\alpha$-synuclein transgenic A53T mice by promoting the aggregation of the $\alpha$-synuclein. These effects are thought to be due to induction of the LRRK2 protein's kinase domain, causing activation of the ERK module [164]. Genetic ablation of LRRK2 in mice had converse effects, suppressing aggregation and delaying 
the development of PD-related pathology [163] as did pharmacological inhibition of ERK in vitro [164]. However, LRRK2 ablation does not appear to be a viable clinical treatment option. The dopaminergic system of LRRK-null mice appears normal, but it is in the kidneys where the loss of the gene has greatest impact, with a 60-fold increase in the accumulation of $\alpha$-synuclein and ubiquitinated proteins in aged animals [165]. LRRK2 loss leads to inflammatory responses, oxidative damage and apoptotic cell death [165], meaning mitochondria may be affected. However, this toxicity induced by oxidative stress has been mapped to be caused by the kinase domain, and ERK inhibition restored cell survival to near-control levels [166]. Therefore, it appears that mitochondria play a relatively minor role in LRRK2related pathology compared to in other gene defects-as demonstrated convincingly by the lack of hypersensitivity to MPTP [161] — with the activity of kinase pathways more involved.

\section{Neuroprotective Methods Targeting Mitochondrial Dysfunction}

Given their position at the centre of a web of cellular functions and pathways and their role in both idiopathic and familial PD, mitochondria constitute a popular target in efforts to protect dopaminergic neurons, thereby arresting degeneration and maintaining the functional capacity of patients.

6.1. Coenzyme Q10. The most well-known mitochondrialtargeting neuroprotective agent is coenzyme Q10 (also known as ubiquinone). The structure functions primarily as an electron acceptor in the electron transport chainshuttling electrons between complexes I and II/III-and a potent antioxidant. It can prevent apoptosis by blocking both the binding of Bax to mitochondrial membranes and cytochrome $c$ release [167] and inhibiting the opening of the $\mathrm{Ca}^{2+}$-gated mitochondrial permeability transition pore (PTP) and the subsequent apoptotic pathway activation [168]. Coenzyme Q10 can directly scavenge free radicals in the inner mitochondrial membrane through interactions with $\alpha$-tocopherol [169]. Reduced levels of coenzyme Q10 in mitochondria isolated from PD patients were found [170], as well as a lower serum level of the enzyme in patients with Parkinsonism compared to stroke patients of similar age [171], which showed the potential supplementation of this agent could have. Treatment with differentiated human neuroblastoma cells showed inhibited ROS formation and cell death induced by the herbicide paraquat in repose to coenzyme Q10 [172], while pretreated rat mesenphalic cells were protected against rotenone-induced apoptosis and mitochondrial depolarisation [173]. Preclinical in vivo studies augmented this theory with evidence that oral supplementation with coenzyme Q10 reduced striatal dopaminergic neuronal loss in MPTP-treated mice [174] and protected against 3-nitroproprionic acid striatal lesions in rats [175]. A clinical trial used a double-blind, placebo-controlled design, and randomly assigned placebo or coenzyme Q10 at doses of
200, 600 or $1200 \mathrm{mg}$ per day to a total of 80 patients with early PD [176]. Patients were rated on the Unified Parkinson's Disease Rating Scale (UPDRS) over a period of 16 months. Coenzyme Q10 was safe and well tolerated at all dose levels, with the group receiving the highest dose developing PD symptoms at the slowest rate-a slowing a 44\%. However, in a study of 130 patients receiving a daily dosage of $300 \mathrm{mg}$, which led to coenzyme Q10 plasma levels of $1200 \mathrm{mg}$, the agent had no symptomatic effect [177]. Therefore, despite mixed results from clinical trials, a strong body of evidence exists to merit further investigation into the therapeutic effects of coenzyme Q10 in PD. A large phase III clinical trial following patients for 16 months is due to be completed in 2011. This study will compare the effects of doses of 1200 and $2400 \mathrm{mg}$ per day and placebo in 600 early stage PD patients [178].

6.2. Creatine. Creatine, a nitrogenous guanisine compound, is another potential mitochondria-targeting treatment that has been investigated to clinical trial level. It occurs naturally in vertebrates (produced endogenously by the liver, kidneys, and pancreas) and helps supply energy to muscle and neurons via its conversion to phosphocreatine. This structure can transfer its phosphoryl group to ADP, thereby creating ATP. This reaction is important in maintaining a ready subcellular supply of ATP. Additional supplies of this compound may be especially valuable during times of cellular stress and dysfunction when energy production is compromised. The addition of creatine has been shown to be useful in a number of models of neurodegenerative diseases, including amytrophic lateral sclerosis [179], Alzheimer's disease [180], and Huntington's disease [181]. In vitro results show significant neuroprotection of dopaminergic cell numbers and morphology against $\mathrm{MPP}^{+}$and 6-OHDA exposure [182]. Oral administration of creatine can protect against MPTP-induced dopaminergic cell loss in mice in a dose-dependent manner [183]; this neuroprotection can be augmented with the addition of the cyclooxygenase2 inhibitor rofecoxib [184]. The long-term (i.e., 2 years) safety of creatine supplementation has been tested in 60 aged PD patients and approved as safe, but the potential risk to patients with underlying renal problems has been identified [185]. However, a blinded, placebo-controlled clinical trial showed no significant difference in the UPDRS scores of 31 patients with PD compared to the 17 placebotreated volunteers after 18 months of treatment [186]. But the test did show a lower requirement for symptomatic treatment in the patients who received creatine, which may represent a degree of dopaminergic signalling protection. This success, however limited, has led to a phase III clinical trial being announced [187]. In addition to monotherapy, a combination of creatine and coenzyme Q10 was found to exert synergistic protective benefits against dopamine depletion and cell loss in the MPTP model [188]. The use of creatine to increase levels of readily available ATP in neurodegenerative diseases is promising. The results of a large-scale clinical trial will further elucidate the potential of its therapeutic efficacy. 
6.3. SS Peptides. These small, synthetic peptide molecules (named after their designers, Hazel Szeto and Peter Schiller) have been utilised thanks to their ability to penetrate numerous types of cells, including dopaminergic neurons, despite carrying a +3 net charge [189]. Relevant to this paper, is the ability of these peptides to enter mitochondria. Evidence for the peptides' capacity to do this began with fluorescent labelling of a SS-02 analogue, which showed colocalisation with a mitochondrial tracker as they concentrated at the inner mitochondrial membrane (IMM) within isolated neurons [190]. This uptake occurs independently of changes in mitochondrial transmembrane potential [191]. The mechanism behind this targeting is not known, but it may be due to an electrostatic attraction between the cationic peptides and the anionic cardiolipin molecules which form in uniquely high density at the IMM [191]. As mitochondrial potential can be diminished in disease states, this membrane potential-independent uptake property may be advantageous.

These mitochondria-targeting peptides have further neuroprotection weapons, including intrinsic dose-dependent antioxidant properties. Peptides such as SS-02 and SS31 can scavenge hydrogen peroxide, hydroxyl radical, and peroxynitrite by virtue of their tyrosine residue $[190,192]$. This activity also inhibits lipid peroxidation. The localisation of SS-02 and SS-31 to the IMM allows the peptides to prevent mitochondrial swelling and depolarisation [190, 192], as shown in $\mathrm{N}_{2} \mathrm{~A}$ neuroblastoma cells when depolarisation was induced by tert-butylhydroperoxide [193]. Specifically relevant to PD, SS-20 and SS- 31 have been shown to be protective in the MPTP mouse model [194]. The latter peptide produced dose-dependent ( 0.1 to $10 \mathrm{mg} / \mathrm{kg}$ ) protection against $\mathrm{SN}$ dopaminergic neuronal loss and maintained striatal levels of dopamine and its metabolites. SS-20 also protected dopaminergic neurons against MPTP insult, despite its lack of intrinsic ROS scavenging ability. Both peptides were very potent in protecting cultured neurons against $\mathrm{MPP}^{+}$-induced cell death, with effectiveness at nanomolar concentrations [194]. Impairment of oxygen consumption, ATP depletion, and mitochondrial swelling were all prevented by the peptides in isolated mitochondria treated with $\mathrm{MPP}^{+}$[194]. Brain uptake of $\mathrm{MPP}^{+}$was not altered in the in vivo study, showing that uptake mechanisms were not altered by the peptides. Thus, the properties outlined above such as ROS scavenging and prevention of apoptosis may be utilised to prevent MPTP toxicity.

These peptides undoubtedly offer a promising mitochondria-targeting treatment for PD. However, data so far has come from one group, so although hitherto positive, results should be treated with caution.

6.4. Natural Antioxidants. A number of naturally occurring antioxidants has been shown to have protective effects against the degeneration induced by elevated ROS levels in cases of mitochondrial dysfunction. There is great depth to the number of potentially beneficial compounds which can be derived naturally; for example, there has been over 4000 species of flavanoids, a group of established plant-derived antioxidants, identified [195]. Green tea polyphenols (GTP) have proven to be protective in SH-SY5Y cells against 6OHDA toxicity [196]. This group find an array of protective effects initiated by GTP including prevention of the decrease in mitochondrial membrane potential, suppressed accumulation of ROS and a scavenging of free radicals in a dose- and time-dependent manner. The efficacy of the green tea component (-)-epigallocatechin 3-gallate (EGCG) has been demonstrated in the MPTP mouse model of $\mathrm{PD}$, with both loss of dopaminergic neurons and striatal dopamine levels attenuated [197, 198] with the authors suggesting that this protection is mediated by the inhibition of NOS expression. But the established antioxidant properties of EGCG also supplement the neuroprotective mechanism, as shown in a yeast-based $\alpha$-synuclein model in which EGCG, along with a further flavonoid, quercetin, increased growth of $\alpha$-synuclein cells though potent antiROS and metal chelating mechanisms [199]. The route of administration of these products is a great advantage of their use, with the drinking of tea having beneficial effects in this study. Epidemiological evidence shows drinking more than two cups a day of green tea has a protective effect against developing PD [200]. The abundance, accessibility, and safety of this beneficial polyphenol make it attractive to study further as a potential clinical preventative agent.

Oxyresveratrol (OXY), a polyphenol found in high amounts in mulberry wood, has displayed potent scavenging activity against reactive oxygen and nitrogen species in glial cells after hydrogen peroxide exposure [201]. The compound is also less cytotoxic to microglial cells than the antioxidant resveratrol [201]. A study in 6-OHDA-treated neuroblastoma SH-SY5Y cells found OXY significantly reduced the generation of ROS and attenuated apoptotic activities of caspase- 3 caused by impaired mitochondria [202]. Adding to the previously realised protective effect OXY has in cerebral ischemia [203] and a profile of OXY as an effective inhibitor of apoptosis and oxidative stress in energy-deprived tissues is becoming established.

Uric acid acts as an antioxidant, scavenging both reactive oxygen and nitrogen species [204]. Epidemiological evidence demonstrates a trend with higher uric acid serum levels correlating with a lower incidence of PD [205-208]. It can also protect against damage to mtDNA by intercepting radicals [209], therefore helping to maintain mitochondrial genomic integrity and prevent the induction of mutations. Uric acid has been found to prevent dopaminergic cell death in rotenone- and homocysteine-treated cells; treatments which cause increased ROS production and exacerbated mitochondrial membrane depolarisation [210]. Guerreiro et al. [211] proposes that uric acid neutralises oxygen species via a Fenton-type chemical reaction, providing in vitro dopaminergic neuroprotection. There is much positive data regarding the antioxidative properties of uric acid, and the ease that urate could be administered (i.e., by diet supplementation) is a major advantage of this treatment. However, the potential benefits of increasing urate levels have to be balanced against the risk of developing gout and cardiovascular problems [212]. Currently, participants are being recruited to study the clinical safety of urate elevation 
in PD (SURE-PD) by dietary supplementation with inosine [213].

Traditional herbal medicines may be effective in attenuating the accumulation of ROS in the event of mitochondrial dysfunction. Cyperi rhizome (CR), the rhizome of Cyperus rotundus, is a traditional herbal medicine used in Korea for stomach disorders. A water extract of CR provided protection in vitro against 6-OHDA-induced toxicity through a number of mechanisms including inhibition of both ROS formation and mitochondrial membrane reduction in the first study of the compound in a neurodegenerative disease model [214]. Uncaria rhynchophylla is a herb that has been used in Oriental medicine to treat hypertension, convulsions and tremor. An extract has proven to be an effective agent against excitotoxicity in hippocampal slices [215]. However, a study examining the antioxidant properties of a range of extracts against lipopolysaccharide-induced NO release found all but one of the 8 compounds tested displayed weak NO inhibitory effects only [216]. A form of this herb, the hook of uncaria rhynchophylla (URH), has proven to be protective in 6-OHDA-treated cells and lesioned rats [217]. In vitro, cell apoptosis and ROS levels were significantly attenuated, while the rats showed reduced dopaminergic cell loss. Further tests in other models may help further establish this extract as an effective antioxidant in the treatment of mitochondrial disorders.

It may be necessary and desirable to look further at this branch of antioxidant agents after the failure to slow disease progression in clinical trials examining agents derived from "modern medicine" $[218,219]$. At present, however, a lack of data in PD models (particularly when compared to other neuroprotective agents discussed in the paper) prevents the true potential and possible clinical value of these antioxidants being comprehensively evaluated. Research of these substances may become more widespread if putative studies continue to deliver promising results.

\section{Conclusion}

The positioning and function of mitochondria make these complex subcellular organelles uniquely susceptible to oxidative damage, and impairment to their vital roles exacerbates damage. Their placement at the centre of a plethora of molecular pathways leads to activation of cell death and apoptotic signal cascades, resulting in degeneration. Further adding to the susceptibility of mitochondria is the presence of their own DNA. The nature of this special genome means that mutations are common, particularly in a structure which routinely produces a baseline level of ROS with an inadequate repair mechanism. These mutations accumulate with age, which adds to the PD pathophysiology, since this is a heavily age-related disorder. The use of several neurotoxins as experimental models to reproduce many of the clinical hallmarks of PD both in vitro and in vivo has allowed the molecular mechanisms of the disease to be investigated further. Common in all types of model is the dysfunction which occurs in mitochondria, often through a direct block of complex I in the electron transport chain, leading to a cascade of further damage. Another milestone discovery in PD research was the delineation of particular proteinencoding genes which, when mutated, lead to the generation of the Parkinsonian phenotype. These mutations are familial in nature, lending subpopulations a degree of susceptibility. The genes allowed further analysis of PD pathogenesis, with mitochondrial dysfunction again proving a deleterious factor. Thus, impairment of these energy-producing organelles provides a link between the common idiopathic form of PD and the rare inherited form of the disease. This makes mitochondria an attractive target for neuroprotective strategies to halt neurodegeneration. Supplementation of Coenzyme Q10 and creatine are methods which have proved successful at pre-clinical level and have been tested in clinical trials, with mixed results. Larger-scale clinical trials, using the information found from previous studies in humans, could help get the best out of these promising strategies. The generation of small peptides, which possess many properties desired in neuroprotective agents, have also shown potential. Various natural antioxidants, including green tea polyphenols, uric acid and extracts from Oriental herbs, have shown potent antioxidant effects, with some demonstrating neuroprotective benefits in a bioenergetically challenged environment, although relatively few studies of these substances in PD models have been carried out. The centring of mitochondria in the pathogenesis of both idiopathic and familial forms of PD mean further neuroprotective strategies should target mitochondria, directly or indirectly, to counter the deleterious and degenerating effects that occur as a consequence of their dysfunction. The ability of present models to recreate mitochondrial impairment to such a degree should allow this process to be tested vigorously and with great accuracy in the laboratory before being presented at the clinical stage.

\section{References}

[1] W. Dauer and S. Przedborski, "Parkinson's disease: mechanisms and models," Neuron, vol. 39, no. 6, pp. 889-909, 2003.

[2] S. Fahn, "The spectrum of levodopa-induced dyskinesias," Annals of Neurology, vol. 47, no. 4, supplement 1, pp. S2-S11, 2000.

[3] L. M. de Lau and M. M. Breteler, "Epidemiology of Parkinson's disease," Lancet Neurology, vol. 5, no. 6, pp. 525535, 2006.

[4] F. Schuler and J. E. Casida, "Functional coupling of PSST and ND1 subunits in NADH:ubiquinone oxidoreductase established by photoaffinity labeling," Biochimica et Biophysica Acta-Bioenergetics, vol. 1506, no. 1, pp. 79-87, 2001.

[5] J. M. Skehel, I. M. Fearnley, and J. E. Walker, "NADH:Ubiquinone oxidoreductase from bovine heart mitochondria: sequence of a novel 17.2-kDa subunit," FEBS Letters, vol. 438, no. 3, pp. 301-305, 1998.

[6] D. Blum, S. Torch, N. Lambeng et al., "Molecular pathways involved in the neurotoxicity of 6-OHDA, dopamine and MPTP: contribution to the apoptotic theory in Parkinson's disease," Progress in Neurobiology, vol. 65, no. 2, pp. 135-172, 2001.

[7] C. Perier, J. Bové, D. C. Wu et al., “Two molecular pathways initiate mitochondria-dependent dopaminergic neurodegeneration in experimental Parkinson's disease," Proceedings of 
the National Academy of Sciences of the United States of America, vol. 104, no. 19, pp. 8161-8166, 2007.

[8] A. Hartmann, J. D. Troadec, S. Hunot et al., "Caspase-8 is an effector in apoptotic death of dopaminergic neurons in Parkinson's disease, but pathway inhibition results in neuronal necrosis," Journal of Neuroscience, vol. 21, no. 7, pp. 2247-2255, 2001.

[9] C. Perier, K. Tieu, C. Guégan et al., "Complex I deficiency primes Bax-dependent neuronal apoptosis through mitochondrial oxidative damage," Proceedings of the National Academy of Sciences of the United States of America, vol. 102, no. 52, pp. 19126-19131, 2005.

[10] P. Li, D. Nijhawan, I. Budihardjo et al., "Cytochrome c and dATP-dependent formation of Apaf-1/caspase-9 complex initiates an apoptotic protease cascade," Cell, vol. 91, no. 4, pp. 479-489, 1997.

[11] M. Vila, V. Jackson-Lewis, S. Vukosavic et al., "Bax ablation prevents dopaminergic neurodegeneration in the 1methyl-4-phenyl-1,2,3,6-tetrahydropyridine mouse model of Parkinson's disease," Proceedings of the National Academy of Sciences of the United States of America, vol. 98, no. 5, pp. 2837-2842, 2001.

[12] G. U. Höglinger, G. Carrard, P. P. Michel et al., "Dysfunction of mitochondrial complex I and the proteasome: interactions between two biochemical deficits in a cellular model of Parkinson's disease," Journal of Neurochemistry, vol. 86, no. 5, pp. 1297-1307, 2003.

[13] A. Williams, "MPTP parkinsonism," British Medical Journal, vol. 289, no. 6456, pp. 1401-1402, 1984.

[14] J. W. Langston, P. Ballard, J. W. Tetrud, and I. Irwin, "Chronic parkinsonism in humans due to a product of meperidineanalog synthesis," Science, vol. 219, no. 4587, pp. 979-980, 1983.

[15] T. D. Buckman, R. Chang, M. S. Sutphin, and S. Eiduson, "Interaction of 1-methyl-4-phenylpyridinium ion with human platelets," Biochemical and Biophysical Research Communications, vol. 151, no. 2, pp. 897-904, 1988.

[16] J. Bové, D. Prou, C. Perier, and S. Przedborski, "Toxininduced models of Parkinson's disease," NeuroRx, vol. 2, no. 3, pp. 484-494, 2005.

[17] A. H. V. Schapira, J. M. Cooper, D. Dexter, P. Jenner, J. B. Clark, and C. D. Marsden, "Mitochondrial complex I deficiency in Parkinson's disease," Lancet, vol. 1, no. 8649, p. 1269, 1989.

[18] P. M. Keeney, J. Xie, R. A. Capaldi, and J. P. Bennett, "Parkinson's disease brain mitochondrial complex I has oxidatively damaged subunits and is functionally impaired and misassembled," Journal of Neuroscience, vol. 26, no. 19, pp. 5256-5264, 2006.

[19] W. D. Parker Jr., S. J. Boyson, and J. K. Parks, "Abnormalities of the electron transport chain in idiopathic Parkinson's disease," Annals of Neurology, vol. 26, no. 6, pp. 719-723, 1989.

[20] L. A. Bindoff, M. A. Birch-Machin, N. E. F. Cartlidge, W. D. Parker Jr., and D. M. Turnbull, "Respiratory chain abnormalities in skeletal muscle from patients with Parkinson's disease," Journal of the Neurological Sciences, vol. 104, no. 2, pp. 203-208, 1991.

[21] D. T. Dexter, C. J. Carter, F. R. Wells et al., "Basal lipid peroxidation in substantia nigra is increased in Parkinson's disease," Journal of Neurochemistry, vol. 52, no. 2, pp. 381$389,1989$.
[22] Z. I. Alam, S. E. Daniel, A. J. Lees, D. C. Marsden, P. Jenner, and B. Halliwell, "A generalised increase in protein carbonyls in the brain in Parkinson's but not incidental Lewy body disease," Journal of Neurochemistry, vol. 69, no. 3, pp. 13261329, 1997.

[23] E. Floor and M. G. Wetzel, "Increased protein oxidation in human substantia nigra pars compacta in comparison with basal ganglia and prefrontal cortex measured with an improved dinitrophenylhydrazine assay," Journal of Neurochemistry, vol. 70, no. 1, pp. 268-275, 1998.

[24] J. Poirier, D. Dea, A. Baccichet, and C. Thiffault, "Superoxide dismutase expression in Parkinson's disease," Annals of the New York Academy of Sciences, vol. 738, pp. 116-120, 1994.

[25] S. Przedborski and V. Jackson-Lewis, "Mechanisms of MPTP toxicity," Movement Disorders, vol. 13, no. 1, pp. 35-38, 1998.

[26] K. Kitahama, R. M. Denney, T. Maeda, and M. Jouvet, "Distribution of type B monoamine oxidase immunoreactivity in the cat brain with reference to enzyme histochemistry," Neuroscience, vol. 44, no. 1, pp. 185-204, 1991.

[27] S. Przedborski and M. Vila, "MPTP: a review of its mechanisms of neurotoxicity," Clinical Neuroscience Research, vol. 1, no. 6, pp. 407-418, 2001.

[28] J. A. Javitch, R. J. D'Amato, S. M. Strittmatter, and S. H. Snyder, "Parkinsonism-inducing neurotoxin, N-methyl-4phenyl-1,2,3,6-tetrahydropyridine: uptake of the metabolite $\mathrm{N}$-methyl-4-phenylpyridine by dopamine neurons explains selective toxicity," Proceedings of the National Academy of Sciences of the United States of America, vol. 82, no. 7, pp. 2173-2177, 1985.

[29] R. A. Mayer, M. V. Kindt, and R. E. Heikkila, "Prevention of the nigrostriatal toxicity of 1-methyl4-phenyl-1,2,3,6-tetrahydropyridine by inhibitors of 3,4-dihydroxyphenylethylamine transport," Journal of Neurochemistry, vol. 47, no. 4, pp. 1073-1079, 1986.

[30] E. Bezard, C. E. Gross, M. C. Fournier, S. Dovero, B. Bloch, and M. Jaber, "Absence of MPTP-induced neuronal death in mice lacking the dopamine transporter," Experimental Neurology, vol. 155, no. 2, pp. 268-273, 1999.

[31] S. Przedborski and M. Vila, "The 1-methyl-4-phenyl-1,2,3,6tetrahydropyridine mouse model: a tool to explore the pathogenesis of Parkinson's disease," Annals of the New York Academy of Sciences, vol. 991, pp. 189-198, 2003.

[32] Y. Liu, A. Roghani, and R. H. Edwards, "Gene transfer of a reserpine-sensitive mechanism of resistance to N- methyl-4phenylpyridinium," Proceedings of the National Academy of Sciences of the United States of America, vol. 89, no. 19, pp. 9074-9078, 1992.

[33] L. K. Klaidman, J. D. Adams Jr., A. C. Leung, S. S. Kim, and E. Cadenas, "Redox cycling of $\mathrm{MPP}^{+}$: evidence for a new mechanism involving hydride transfer with xanthine oxidase, aldehyde dehydrogenase, and lipoamide dehydrogenase," Free Radical Biology and Medicine, vol. 15, no. 2, pp. 169-179, 1993.

[34] R. R. Ramsay and T. P. Singer, "Energy-dependent uptake of N-methyl-4-phenylpyridinium, the neurotoxic metabolite of 1-methyl-4-phenyl-1,2,3,6-tetrahydropyridine, by mitochondria," Journal of Biological Chemistry, vol. 261, no. 17, pp. 7585-7587, 1986.

[35] Y. Mizuno, T. Saitoh, and N. Sone, "Inhibition of mitochondrial alpha-ketoglutarate dehydrogenase by 1-methyl-4phenylpyridinium ion," Biochemical and Biophysical Research Communications, vol. 143, no. 3, pp. 971-976, 1987. 
[36] R. R. Ramsay, M. J. Krueger, S. K. Youngster, M. R. Gluck, J. E. Casida, and T. P. Singer, "Interaction of 1-methyl4-phenylpyridinium ion (MPP) and its analogs with the rotenone/piericidin binding site of NADH dehydrogenase," Journal of Neurochemistry, vol. 56, no. 4, pp. 1184-1190, 1991.

[37] S. Przedborski, K. Tieu, C. Perier, and M. Vila, "MPTP as a mitochondrial neurotoxic model of Parkinson's disease," Journal of Bioenergetics and Biomembranes, vol. 36, no. 4, pp. 375-379, 2004.

[38] P. Chan, L. E. DeLanney, I. Irwin, J. W. Langston, and D. Di Monte, "Rapid ATP loss caused by 1-methyl-4phenyl-1,2,3,6-tetrahydropyridine in mouse brain," Journal of Neurochemistry, vol. 57, no. 1, pp. 348-351, 1991.

[39] E. Fahre, J. Monserrat, A. Herrero, G. Barja, and M. L. Leret, "Effect of MPTP on brain mitochondrial $\mathrm{H}_{2} \mathrm{O}_{2}$ and ATP production and on dopamine and DOPAC in the striatum," Journal of Physiology and Biochemistry, vol. 55, no. 4, pp. 325332, 1999.

[40] G. P. Davey and J. B. Clark, "Threshold effects and control of oxidative phosphorylation in nonsynaptic rat brain mitochondria," Journal of Neurochemistry, vol. 66, no. 4, pp. 1617$1624,1996$.

[41] W. S. Choi, S. E. Kruse, R. D. Palmiter, and Z. Xia, "Mitochondrial complex I inhibition is not required for dopaminergic neuron death induced by rotenone, $\mathrm{MPP}^{+}$, or paraquat," Proceedings of the National Academy of Sciences of the United States of America, vol. 105, no. 39, pp. 1513615141, 2008.

[42] K. Tieu, C. Perier, C. Caspersen et al., "D- $\beta$-Hydroxybutyrate rescues mitochondrial respiration and mitigates features of Parkinson disease," Journal of Clinical Investigation, vol. 112, no. 6, pp. 892-901, 2003.

[43] M. F. Beal, Rascol, Marek et al., "Bioenergetic approaches for neuroprotection in Parkinson's disease," Annals of Neurology, vol. 53, no. 3, pp. S39-S48, 2003.

[44] G. T. Liberatore, V. Jackson-Lewis, S. Vukosavic et al., "Inducible nitric oxide synthase stimulates dopaminergic neurodegeneration in the MPTP model of Parkinson disease," Nature Medicine, vol. 5, no. 12, pp. 1403-1409, 1999.

[45] S. Przedborski, V. Kostic, V. Jackson-Lewis et al., "Transgenic mice with increased $\mathrm{Cu} / \mathrm{Zn}$-superoxide dismutase activity are resistant to N-methyl-4-phenyl-1,2,3,6-tetrahydropyridineinduced neurotoxicity," Journal of Neuroscience, vol. 12, no. 5, pp. 1658-1667, 1992.

[46] L. A. Sturtz, K. Diekert, L. T. Jensen, R. Lill, and V. C. Culotta, "A fraction of yeast $\mathrm{Cu}, \mathrm{Zn}$-superoxide dismutase and its metallochaperone, CCS, localize to the intermembrane space of mitochondria. A physiological role for SOD1 in guarding against mitochondrial oxidative damage," Journal of Biological Chemistry, vol. 276, no. 41, pp. 38084-38089, 2001.

[47] P. Jenner and C. W. Olanow, "Understanding cell death in Parkinson's disease," Annals of Neurology, vol. 44, no. 3, pp. S72-S84, 1998.

[48] B. Dehay, J. Bové, N. Rodríguez-Muela et al., "Pathogenic lysosomal depletion in Parkinson's disease," Journal of Neuroscience, vol. 30, no. 37, pp. 12535-12544, 2010.

[49] J. P. Luzio, P. R. Pryor, and N. A. Bright, "Lysosomes: fusion and function," Nature Reviews Molecular Cell Biology, vol. 8, no. 8, pp. 622-632, 2007.

[50] C. Malagelada, Z. H. Jin, V. Jackson-Lewis, S. Przedborski, and L. A. Greene, "Rapamycin protects against neuron death in in vitro and in vivo models of Parkinson's disease," Journal of Neuroscience, vol. 30, no. 3, pp. 1166-1175, 2010.
[51] A. Elbaz and C. Tranchant, "Epidemiologic studies of environmental exposures in Parkinson's disease," Journal of the Neurological Sciences, vol. 262, no. 1-2, pp. 37-44, 2007.

[52] J. M. Gorell, E. L. Peterson, B. A. Rybicki, and C. C. Johnson, "Multiple risk factors for Parkinson's disease," Journal of the Neurological Sciences, vol. 217, no. 2, pp. 169-174, 2004.

[53] T. B. Sherer, R. Betarbet, C. M. Testa et al., "Mechanism of toxicity in rotenone models of Parkinson's disease," Journal of Neuroscience, vol. 23, no. 34, pp. 10756-10764, 2003.

[54] D. J. Talpade, J. G. Greene, D. S. Higgins, and J. T. Greenamyre, "In vivo labeling of mitochondrial complex I (NADH:Ubiquinone oxidoreductase) in rat brain using $\left[{ }^{3} \mathrm{H}\right]$ dihydrorotenone," Journal of Neurochemistry, vol. 75, no. 6, pp. 2611-2621, 2000.

[55] T. B. Sherer, J. H. Kim, R. Betarbet, and J. T. Greenamyre, "Subcutaneous rotenone exposure causes highly selective dopaminergic degeneration and $\alpha$-synuclein aggregation," Experimental Neurology, vol. 179, no. 1, pp. 9-16, 2003.

[56] R. Betarbet, T. B. Sherer, G. MacKenzie, M. Garcia-Osuna, A. V. Panov, and J. T. Greenamyre, "Chronic systemic pesticide exposure reproduces features of Parkinson's disease," Nature Neuroscience, vol. 3, no. 12, pp. 1301-1306, 2000.

[57] T. M. Dawson and V. L. Dawson, "Molecular pathways of neurodegeneration in Parkinson's disease," Science, vol. 302, no. 5646, pp. 819-822, 2003.

[58] T. Pan, P. Rawal, Y. Wu, W. Xie, J. Jankovic, and W. Le, "Rapamycin protects against rotenone-induced apoptosis through autophagy induction," Neuroscience, vol. 164, no. 2, pp. 541-551, 2009.

[59] S. Senoh, C. R. Creveling, S. Udenfriend, and B. Witkop, "Chemical, enzymatic and metabolic studies on the mechanism of oxidation of dopamine," Journal of the American Chemical Society, vol. 81, no. 23, pp. 6236-6240, 1959.

[60] G. Cohen, "Oxy-radical toxicity in catecholamine neurons," NeuroToxicology, vol. 5, no. 1, pp. 77-82, 1984.

[61] S. M. Kulich and C. T. Chu, "Sustained extracellular signalregulated kinase activation by 6-hydroxydopamine: implications for Parkinson's disease," Journal of Neurochemistry, vol. 77, no. 4, pp. 1058-1066, 2001.

[62] S. M. Kulich, C. Horbinski, M. Patel, and C. T. Chu, "6Hydroxydopamine induces mitochondrial ERK activation," Free Radical Biology and Medicine, vol. 43, no. 3, pp. 372-383, 2007.

[63] L. Margulis, "Symbiosis and evolution," Scientific American, vol. 225, no. 2, pp. 48-57, 1971.

[64] C. Richter, J. W. Park, and B. N. Ames, "Normal oxidative damage to mitochondrial and nuclear DNA is extensive," Proceedings of the National Academy of Sciences of the United States of America, vol. 85, no. 17, pp. 6465-6467, 1988.

[65] A. W. Linnane, S. Marzuki, T. Ozawa, and M. Tanaka, "Mitochondrial DNA mutations as an important contributor to ageing and degenerative diseases," Lancet, vol. 1, no. 8639, pp. 642-645, 1989.

[66] Y. Michikawa, F. Mazzucchelli, N. Bresolin, G. Scarlato, and G. Attardi, "Aging-dependent large accumulation of point mutations in the human mtDNA control region for replication," Science, vol. 286, no. 5440, pp. 774-779, 1999.

[67] D. K. Simon, M. T. Lin, L. Zheng et al., "Somatic mitochondrial DNA mutations in cortex and substantia nigra in aging and Parkinson's disease," Neurobiology of Aging, vol. 25, no. 1, pp. 71-81, 2004. 
[68] R. Smigrodzki, J. Parks, and W. D. Parker, "High frequency of mitochondrial complex I mutations in Parkinson's disease and aging," Neurobiology of Aging, vol. 25, no. 10, pp. 1273 1281, 2004.

[69] C. Vives-Bauza, A. L. Andreu, G. Manfredi et al., "Sequence analysis of the entire mitochondrial genome in Parkinson's disease," Biochemical and Biophysical Research Communications, vol. 290, no. 5, pp. 1593-1601, 2002.

[70] M. Vermulst, J. H. Bielas, G. C. Kujoth et al., "Mitochondrial point mutations do not limit the natural lifespan of mice," Nature Genetics, vol. 39, no. 4, pp. 540-543, 2007.

[71] Y. Kraytsberg, E. Kudryavtseva, A. C. McKee, C. Geula, N. W. Kowall, and K. Khrapko, "Mitochondrial DNA deletions are abundant and cause functional impairment in aged human substantia nigra neurons," Nature Genetics, vol. 38, no. 5, pp. 518-520, 2006.

[72] R. Banerjee, A. A. Starkov, M. F. Beal, and B. Thomas, "Mitochondrial dysfunction in the limelight of Parkinson's disease pathogenesis," Biochimica et Biophysica ActaMolecular Basis of Disease, vol. 1792, no. 7, pp. 651-663, 2009.

[73] Y. Wang, Y. Michikawa, C. Mallidis et al., "Muscle-specific mutations accumulate with aging in critical human mtDNA control sites for replication," Proceedings of the National Academy of Sciences of the United States of America, vol. 98, no. 7, pp. 4022-4027, 2001.

[74] K. Auré, G. Fayet, J. P. Leroy, E. Lacène, N. B. Romero, and A. Lombès, "Apoptosis in mitochondrial myopathies is linked to mitochondrial proliferation," Brain, vol. 129, no. 5, pp. 1249 1259, 2006.

[75] M. Gu, J. M. Cooper, J. W. Taanman, and A. H. V. Schapira, "Mitochondrial DNA transmission of the mitochondrial defect in Parkinson's disease," Annals of Neurology, vol. 44, no. 2, pp. 177-186, 1998.

[76] J. P. Sheehan, R. H. Swerdlow, W. D. Parker, S. W. Miller, R. E. Davis, and J. B. Tuttle, "Altered calcium homeostasis in cells transformed by mitochondria from individuals with Parkinson's disease," Journal of Neurochemistry, vol. 68, no. 3, pp. 1221-1233, 1997.

[77] A. Bender, K. J. Krishnan, C. M. Morris et al., "High levels of mitochondrial DNA deletions in substantia nigra neurons in aging and Parkinson disease," Nature Genetics, vol. 38, no. 5, pp. 515-517, 2006.

[78] A. K. Reeve, K. J. Krishnan, and D. Turnbull, "Mitochondrial DNA mutations in disease, aging, and neurodegeneration," Annals of the New York Academy of Sciences, vol. 1147, pp. 21-29, 2008

[79] E. Ruiz-Pesini, D. Mishmar, M. Brandon, V. Procaccio, and D. C. Wallace, "Effects of purifying and adaptive selection on regional variation in human mtDNA," Science, vol. 303, no. 5655, pp. 223-226, 2004.

[80] J. M. van der Walt, K. K. Nicodemus, E. R. Martin et al., "Mitochondrial polymorphisms significantly reduce the risk of Parkinson disease," American Journal of Human Genetics, vol. 72, no. 4, pp. 804-811, 2003.

[81] A. Pyle, T. Foltynie, W. Tiangyou et al., "Mitochondrial DNA haplogroup cluster UKJT reduces the risk of PD," Annals of Neurology, vol. 57, no. 4, pp. 564-567, 2005.

[82] J. Autere, J. S. Moilanen, S. Finnilä et al., "Mitochondrial DNA polymorphisms as risk factors for Parkinson's disease and Parkinson's disease dementia," Human Genetics, vol. 115, no. 1, pp. 29-35, 2004.
[83] A. M. Lazzarini, R. H. Myers, T. R. Zimmerman Jr. et al., "A clinical genetic study of Parkinson's disease: evidence for dominant transmission," Neurology, vol. 44, no. 3, pp. 499506, 1994.

[84] C. B. Lücking, A. Dürr, V. Bonifati et al., "Association between early-onset Parkinson's disease and mutations in the parkin gene," New England Journal of Medicine, vol. 342, no. 21, pp. 1560-1567, 2000.

[85] V. Bonifati, P. Rizzu, M. J. van Baren et al., "Mutations in the DJ-1 gene associated with autosomal recessive early-onset parkinsonism," Science, vol. 299, no. 5604, pp. 256-259, 2003.

[86] E. M. Valente, P. M. Abou-Sleiman, V. Caputo et al., "Hereditary early-onset Parkinson's disease caused by mutations in PINK1," Science, vol. 304, no. 5674, pp. 1158-1160, 2004.

[87] K. Ueda, H. Fukushima, E. Masliah et al., "Molecular cloning of cDNA encoding an unrecognized component of amyloid in Alzheimer disease," Proceedings of the National Academy of Sciences of the United States of America, vol. 90, no. 23, pp. 11282-11286, 1993.

[88] A. Abeliovich, Y. Schmitz, I. Fariñas et al., "Mice lacking $\alpha$-synuclein display functional deficits in the nigrostriatal dopamine system," Neuron, vol. 25, no. 1, pp. 239-252, 2000.

[89] M. H. Polymeropoulos, C. Lavedan, E. Leroy et al., "Mutation in the $\alpha$-synuclein gene identified in families with Parkinson's disease," Science, vol. 276, no. 5321, pp. 2045-2047, 1997.

[90] R. Krüger, W. Kuhn, T. Müller et al., "Ala30Pro mutation in the gene encoding $\alpha$-synuclein in Parkinson's disease," Nature Genetics, vol. 18, no. 2, pp. 106-108, 1998.

[91] J. J. Zarranz, J. Alegre, J. C. Gómez-Esteban et al., “The new mutation, E46K, of $\alpha$-synuclein causes Parkinson and lewy body dementia," Annals of Neurology, vol. 55, no. 2, pp. 164173, 2004.

[92] A. B. Singleton, M. Farrer, J. Johnson et al., " $\alpha$-synuclein locus triplication causes Parkinson's disease," Science, vol. 302, no. 5646, p. 841, 2003.

[93] S. Büttner, A. Bitto, J. Ring et al., "Functional mitochondria are required for $\alpha$-synuclein toxicity in aging yeast," Journal of Biological Chemistry, vol. 283, no. 12, pp. 7554-7560, 2008.

[94] L. J. Martin, Y. Pan, A. C. Price et al., "Parkinson's disease $\alpha$-synuclein transgenic mice develop neuronal mitochondrial degeneration and cell death," Journal of Neuroscience, vol. 26, no. 1, pp. 41-50, 2006.

[95] L. J. Hsu, Y. Sagara, A. Arroyo et al., " $\alpha$-synuclein promotes mitochondrial deficit and oxidative stress," American Journal of Pathology, vol. 157, no. 2, pp. 401-410, 2000.

[96] M. Hashimoto, A. Takeda, L. J. Hsu, T. Takenouchi, and E. Masliah, "Role of cytochrome c as a stimulator of $\alpha$-synuclein aggregation in Lewy body disease," Journal of Biological Chemistry, vol. 274, no. 41, pp. 28849-28852, 1999.

[97] C. A. Da Costa, K. Ancolio, and F. Checler, "Wild-type but not Parkinson's disease-related Ala-53 $\rightarrow$ Thr mutant $\alpha$ Synuclein protects neuronal cells from apoptotic stimuli," Journal of Biological Chemistry, vol. 275, no. 31, pp. 2406524069, 2000.

[98] C. Alves Da Costa, E. Paitel, B. Vincent, and F. Checler, " $\alpha$-synuclein lowers p53-dependent apoptotic response of neuronal cells: abolishment by 6-hydroxydopamine and implication for Parkinson's disease," Journal of Biological Chemistry, vol. 277, no. 52, pp. 50980-50984, 2002.

[99] Y. Tanaka, S. Engelender, S. Igarashi et al., "Inducible expression of mutant $\alpha$-synuclein decreases proteasome activity and increases sensitivity to mitochondria-dependent apoptosis," Human Molecular Genetics, vol. 10, no. 9, pp. 919-926, 2001. 
[100] L. Devi, V. Raghavendran, B. M. Prabhu, N. G. Avadhani, and H. K. Anandatheerthavarada, "Mitochondrial import and accumulation of $\alpha$-synuclein impair complex I in human dopaminergic neuronal cultures and Parkinson disease brain," Journal of Biological Chemistry, vol. 283, no. 14, pp. 9089-9100, 2008.

[101] M. S. Parihar, A. Parihar, M. Fujita, M. Hashimoto, and P. Ghafourifar, "Alpha-synuclein overexpression and aggregation exacerbates impairment of mitochondrial functions by augmenting oxidative stress in human neuroblastoma cells," International Journal of Biochemistry and Cell Biology, vol. 41, no. 10, pp. 2015-2024, 2009.

[102] M. S. Parihar, A. Parihar, M. Fujita, M. Hashimoto, and P. Ghafourifar, "Mitochondrial association of alpha-synuclein causes oxidative stress," Cellular and Molecular Life Sciences, vol. 65, no. 7-8, pp. 1272-1284, 2008.

[103] HE. J. Lee, S. Y. Shin, C. Choi, Y. H. Lee, and S. J. Lee, "Formation and removal of $\alpha$-synuclein aggregates in cells exposed to mitochondrial inhibitors," Journal of Biological Chemistry, vol. 277, no. 7, pp. 5411-5417, 2002.

[104] W. Dauer, N. Kholodilov, M. Vila et al., "Resistance of $\alpha$ synuclein null mice to the parkinsonian neurotoxin MPTP," Proceedings of the National Academy of Sciences of the United States of America, vol. 99, no. 22, pp. 14524-14529, 2002.

[105] P. Klivenyi, D. Siwek, G. Gardian et al., "Mice lacking alphasynuclein are resistant to mitochondrial toxins," Neurobiology of Disease, vol. 21, no. 3, pp. 541-548, 2006.

[106] N. B. Cole, D. DiEuliis, P. Leo, D. C. Mitchell, and R. L. Nussbaum, "Mitochondrial translocation of $\alpha$-synuclein is promoted by intracellular acidification," Experimental Cell Research, vol. 314, no. 10, pp. 2076-2089, 2008.

[107] T. Kitada, S. Asakawa, N. Hattori et al., "Mutations in the parkin gene cause autosomal recessive juvenile parkinsonism," Nature, vol. 392, no. 6676, pp. 605-608, 1998.

[108] A. B. West and N. T. Maidment, "Genetics of parkin-linked disease," Human Genetics, vol. 114, no. 4, pp. 327-336, 2004.

[109] D. J. Moore, "Parkin: a multifaceted ubiquitin ligase," Biochemical Society Transactions, vol. 34, no. 5, pp. 749-753, 2006.

[110] H. Shimura, N. Hattori, S. I. Kubo et al., "Familial Parkinson disease gene product, parkin, is a ubiquitin-protein ligase," Nature Genetics, vol. 25, no. 3, pp. 302-305, 2000.

[111] C. M. Pickart and D. Fushman, "Polyubiquitin chains: polymeric protein signals," Current Opinion in Chemical Biology, vol. 8, no. 6, pp. 610-616, 2004.

[112] F. Darios, O. Corti, C. B. Lücking et al., "Parkin prevents mitochondrial swelling and cytochrome c release in mitochondria-dependent cell death," Human Molecular Genetics, vol. 12, no. 5, pp. 517-526, 2003.

[113] A. K. Berger, G. P. Cortese, K. D. Amodeo, A. Weihofen, A. Letai, and M. J. LaVoie, "Parkin selectively alters the intrinsic threshold for mitochondrial cytochrome c release," Human Molecular Genetics, vol. 18, no. 22, pp. 4317-4328, 2009.

[114] Y. Kuroda, T. Mitsui, M. Kunishige et al., "Parkin enhances mitochondrial biogenesis in proliferating cells," Human Molecular Genetics, vol. 15, no. 6, pp. 883-895, 2006.

[115] J. J. Palacino, D. Sagi, M. S. Goldberg et al., "Mitochondrial dysfunction and oxidative damage in parkin-deficient mice," Journal of Biological Chemistry, vol. 279, no. 18, pp. 18614 18622, 2004

[116] M. S. Goldberg, S. M. Fleming, J. J. Palacino et al., "Parkindeficient mice exhibit nigrostriatal deficits but not loss of dopaminergic neurons," Journal of Biological Chemistry, vol. 278, no. 44, pp. 43628-43635, 2003.
[117] C. C. Stichel, X. R. Zhu, V. Bader, B. Linnartz, S. Schmidt, and H. Lübbert, "Mono- and double-mutant mouse models of Parkinson's disease display severe mitochondrial damage," Human Molecular Genetics, vol. 16, no. 20, pp. 2377-2393, 2007.

[118] H. Mortiboys, K. J. Thomas, W. J. H. Koopman et al., "Mitochondrial function and morphology are impaired in parkin-mutant fibroblasts," Annals of Neurology, vol. 64, no. 5, pp. 555-565, 2008.

[119] Y. Pesah, T. Pham, H. Burgess et al., "Drosophila parkin mutants have decreased mass and cell size and increased sensitivity to oxygen radical stress," Development, vol. 131, no. 9, pp. 2183-2194, 2004.

[120] O. Rothfuss, H. Fischer, T. Hasegawa et al., "Parkin protects mitochondrial genome integrity and supports mitochondrial DNA repair," Human Molecular Genetics, vol. 18, no. 20, pp. 3832-3850, 2009.

[121] H. Deng, J. Jankovic, Y. Guo, W. Xie, and W. Le, "Small interfering RNA targeting the PINK1 induces apoptosis in dopaminergic cells SH-SY5Y," Biochemical and Biophysical Research Communications, vol. 337, no. 4, pp. 1133-1138, 2005.

[122] A. Petit, T. Kawarai, E. Paitel et al., "Wild-type PINK1 prevents basal and induced neuronal apoptosis, a protective effect abrogated by Parkinson disease-related mutations," Journal of Biological Chemistry, vol. 280, no. 40, pp. 3402534032, 2005.

[123] M. E. Haque, K. J. Thomas, C. D’Souza et al., “Cytoplasmic Pink1 activity protects neurons from dopaminergic neurotoxin MPTP," Proceedings of the National Academy of Sciences of the United States of America, vol. 105, no. 5, pp. 1716-1721, 2008.

[124] S. Gandhi, M. M. K. Muqit, L. Stanyer et al., "PINK1 protein in normal human brain and Parkinson's disease," Brain, vol. 129, no. 7, pp. 1720-1731, 2006.

[125] C. Zhou, Y. Huang, Y. Shao et al., "The kinase domain of mitochondrial PINK1 faces the cytoplasm," Proceedings of the National Academy of Sciences of the United States of America, vol. 105, no. 33, pp. 12022-12027, 2008.

[126] I. E. Clark, M. W. Dodson, C. Jiang et al., "Drosophila pink1 is required for mitochondrial function and interacts genetically with parkin," Nature, vol. 441, no. 7097, pp. 11621166, 2006.

[127] J. Park, S. B. Lee, S. Lee et al., "Mitochondrial dysfunction in Drosophila PINK1 mutants is complemented by parkin," Nature, vol. 441, no. 7097, pp. 1157-1161, 2006.

[128] Y. Yang, S. Gehrke, Y. Imai et al., "Mitochondrial pathology and muscle and dopaminergic neuron degeneration caused by inactivation of Drosophila Pink1 is rescued by Parkin," Proceedings of the National Academy of Sciences of the United States of America, vol. 103, no. 28, pp. 10793-10798, 2006.

[129] N. Exner, B. Treske, D. Paquet et al., "Loss-of-function of human PINK1 results in mitochondrial pathology and can be rescued by parkin," Journal of Neuroscience, vol. 27, no. 45, pp. 12413-12418, 2007.

[130] S. J. Goldman Scott, R. Taylor, Y. Zhang, and S. Jin, "Autophagy and the degradation of mitochondria," Mitochondrion, vol. 10, no. 4, pp. 309-315, 2010.

[131] I. Kim, S. Rodriguez-Enriquez, and J. J. Lemasters, "Selective degradation of mitochondria by mitophagy," Archives of Biochemistry and Biophysics, vol. 462, no. 2, pp. 245-253, 2007. 
[132] S. J. Chinta, J. K. Mallajosyula, A. Rane, and J. K. Andersen, "Mitochondrial alpha-synuclein accumulation impairs complex I function in dopaminergic neurons and results in increased mitophagy in vivo," Neuroscience Letters, vol. 486, no. 3, pp. 235-239, 2010.

[133] Y. Chu, H. Dodiya, P. Aebischer, C. W. Olanow, and J. H. Kordower, "Alterations in lysosomal and proteasomal markers in Parkinson's disease: relationship to alpha-synuclein inclusions," Neurobiology of Disease, vol. 35, no. 3, pp. 385398, 2009.

[134] V. Cullen, M. Lindfors, J. Ng et al., "Cathepsin D expression level affects alpha-synuclein processing, aggregation, and toxicity in vivo," Molecular Brain, vol. 2, no. 1, article 5, 2009.

[135] D. Narendra, A. Tanaka, D. F. Suen, and R. J. Youle, "Parkin is recruited selectively to impaired mitochondria and promotes their autophagy," Journal of Cell Biology, vol. 183, no. 5, pp. 795-803, 2008.

[136] D. P. Narendra, S. M. Jin, A. Tanaka et al., "PINK1 is selectively stabilized on impaired mitochondria to activate Parkin," PLoS Biology, vol. 8, no. 1, Article ID e1000298, 2010.

[137] N. Matsuda, S. Sato, K. Shiba et al., "PINK1 stabilized by mitochondrial depolarization recruits Parkin to damaged mitochondria and activates latent Parkin for mitophagy," Journal of Cell Biology, vol. 189, no. 2, pp. 211-221, 2010.

[138] Q. Ruan, A. J. Harrington, K. A. Caldwell, G. A. Caldwell, and D. G. Standaert, "VPS41, a protein involved in lysosomal trafficking, is protective in Caenorhabditis elegans and mammalian cellular models of Parkinson's disease," Neurobiology of Disease, vol. 37, no. 2, pp. 330-338, 2010.

[139] C. Vives-Bauza, C. Zhou, Y. Huang et al., "PINK1-dependent recruitment of Parkin to mitochondria in mitophagy," Proceedings of the National Academy of Sciences of the United States of America, vol. 107, no. 1, pp. 378-383, 2010.

[140] R. K. Dagda, S. J. Cherra III, S. M. Kulich, A. Tandon, D. Park, and C. T. Chu, "Loss of PINK1 function promotes mitophagy through effects on oxidative stress and mitochondrial fission," Journal of Biological Chemistry, vol. 284, no. 20, pp. 13843-13855, 2009.

[141] H. Deng, M. W. Dodson, H. Huang, and M. Guo, "The Parkinson's disease genes pink1 and parkin promote mitochondrial fission and/or inhibit fusion in Drosophila," Proceedings of the National Academy of Sciences of the United States of America, vol. 105, no. 38, pp. 14503-14508, 2008.

[142] A. C. Poole, R. E. Thomas, L. A. Andrews, H. M. McBride, A. J. Whitworth, and L. J. Pallanck, "The PINK1/Parkin pathway regulates mitochondrial morphology," Proceedings of the National Academy of Sciences of the United States of America, vol. 105, no. 5, pp. 1638-1643, 2008.

[143] J. Park, G. Lee, and J. Chung, "The PINK1-Parkin pathway is involved in the regulation of mitochondrial remodeling process," Biochemical and Biophysical Research Communications, vol. 378, no. 3, pp. 518-523, 2009.

[144] C. A. Gautier, T. Kitada, and J. Shen, "Loss of PINK1 causes mitochondrial functional defects and increased sensitivity to oxidative stress," Proceedings of the National Academy of Sciences of the United States of America, vol. 105, no. 32, pp. 11364-11369, 2008.

[145] C. Piccoli, A. Sardanelli, R. Scrima et al., "Mitochondrial respiratory dysfunction in familiar Parkinsonism associated with PINK1 mutation," Neurochemical Research, vol. 33, no. 12, pp. 2565-2574, 2008.

[146] T. Taira, Y. Saito, T. Niki, S. M. M. Iguchi-Ariga, K. Takahashi, and H. Ariga, "DJ-1 has a role in antioxidative stress to prevent cell death," EMBO Reports, vol. 5, no. 2, pp. 213-218, 2004.

[147] N. Lev, D. Ickowicz, E. Melamed, and D. Offen, "Oxidative insults induce DJ-1 upregulation and redistribution: implications for neuroprotection," NeuroToxicology, vol. 29, no. 3, pp. 397-405, 2008.

[148] M. Meulener, A. J. Whitworth, C. E. Armstrong-Gold et al., "Drosophila DJ-1 mutants are selectively sensitive to environmental toxins associated with Parkinson's disease," Current Biology, vol. 15, no. 17, pp. 1572-1577, 2005.

[149] M. C. Meulener, K. Xu, L. Thompson, H. Ischiropoulos, and N. M. Bonini, "Mutational analysis of DJ-1 in Drosophila implicates functional inactivation by oxidative damage and aging," Proceedings of the National Academy of Sciences of the United States of America, vol. 103, no. 33, pp. 12517-12522, 2006.

[150] R. H. Kim, P. D. Smith, H. Aleyasin et al., "Hypersensitivity of DJ-1-deficient mice to 1-methyl-4-phenyl-1,2,3,6- tetrahydropyrindine (MPTP) and oxidative stress," Proceedings of the National Academy of Sciences of the United States of America, vol. 102, no. 14, pp. 5215-5220, 2005.

[151] C. Martinat, S. Shendelman, A. Jonason et al., "Sensitivity to oxidative stress in DJ-1-deficient dopamine neurons: an ESderived cell model of primary Parkinsonism," PLoS Biology, vol. 2, no. 11, 2004.

[152] S. Shendelman, A. Jonason, C. Martinat, T. Leete, and A. Abeliovich, "DJ-1 is a redox-dependent molecular chaperone that inhibits $\alpha$-synuclein aggregate formation," PLoS Biology, vol. 2, no. 11, article e362, 2004.

[153] W. Yang, L. Chen, Y. Ding, X. Zhuang, and U. J. Kang, "Paraquat induces dopaminergic dysfunction and proteasome impairment in DJ-1-deficient mice," Human Molecular Genetics, vol. 16, no. 23, pp. 2900-2910, 2007.

[154] J. Y. Im, K. W. Lee, E. Junn, and M. M. Mouradian, "DJ-1 protects against oxidative damage by regulating the thioredoxin/ASK1 complex," Neuroscience Research, vol. 67, no. 3, pp. 203-208, 2010.

[155] T. Hayashi, C. Ishimori, K. Takahashi-Niki et al., "DJ-1 binds to mitochondrial complex I and maintains its activity," Biochemical and Biophysical Research Communications, vol. 390, no. 3, pp. 667-672, 2009.

[156] E. Andres-Mateos, C. Perier, L. Zhang et al., "DJ-1 gene deletion reveals that DJ-1 is an atypical peroxiredoxin-like peroxidase," Proceedings of the National Academy of Sciences of the United States of America, vol. 104, no. 37, pp. 1480714812, 2007.

[157] A. Zimprich, S. Biskup, P. Leitner et al., "Mutations in LRRK2 cause autosomal-dominant parkinsonism with pleomorphic pathology," Neuron, vol. 44, no. 4, pp. 601-607, 2004.

[158] L. Bosgraaf and P. J. M. van Haastert, "Roc, a Ras/GTPase domain in complex proteins," Biochimica et Biophysica Acta-Molecular Cell Research, vol. 1643, no. 1-3, pp. 5-10, 2003.

[159] A. B. West, D. J. Moore, S. Biskup et al., "Parkinson's disease-associated mutations in leucine-rich repeat kinase 2 augment kinase activity," Proceedings of the National Academy of Sciences of the United States of America, vol. 102, no. 46, pp. 16842-16847, 2005.

[160] C. J. Gloeckner, N. Kinkl, A. Schumacher et al., "The Parkinson disease causing LRRK2 mutation I2020T is associated with increased kinase activity," Human Molecular Genetics, vol. 15, no. 2, pp. 223-232, 2006. 
[161] E. Andres-Mateos, R. Mejias, M. Sasaki et al., "Unexpected lack of hypersensitivity in LRRK2 knock-out mice to MPTP (1-methyl-4-phenyl-1,2,3,6-tetrahydropyridine)," Journal of Neuroscience, vol. 29, no. 50, pp. 15846-15850, 2009.

[162] A. B. West, D. J. Moore, C. Choi et al., "Parkinson's diseaseassociated mutations in LRRK2 link enhanced GTP-binding and kinase activities to neuronal toxicity," Human Molecular Genetics, vol. 16, no. 2, pp. 223-232, 2007.

[163] X. Lin, L. Parisiadou, X. L. Gu et al., "Leucine-rich repeat kinase 2 regulates the progression of neuropathology induced by Parkinson's-disease-related mutant $\alpha$-synuclein," Neuron, vol. 64, no. 6, pp. 807-827, 2009.

[164] I. Carballo-Carbajal, S. Weber-Endress, G. Rovelli et al., "Leucine-rich repeat kinase 2 induces alpha-synuclein expression via the extracellular signal-regulated kinase pathway," Cellular Signalling, vol. 22, no. 5, pp. 821-827, 2010.

[165] Y. Tong, H. Yamaguchi, E. Giaime et al., "Loss of leucine-rich repeat kinase 2 causes impairment of protein degradation pathways, accumulation of $\alpha$-synuclein, and apoptotic cell death in aged mice," Proceedings of the National Academy of Sciences of the United States of America, vol. 107, no. 21, pp. 9879-9884, 2010.

[166] H. Y. Heo, J. M. Park, C. H. Kim, B. S. Han, K. S. Kim, and W. Seol, "LRRK2 enhances oxidative stress-induced neurotoxicity via its kinase activity," Experimental Cell Research, vol. 316, no. 4, pp. 649-656, 2010.

[167] J. Naderi, M. Somayajulu-Nitu, A. Mukerji et al., "Watersoluble formulation of Coenzyme $\mathrm{Q}_{10}$ inhibits Bax-induced destabilization of mitochondria in mammalian cells," Apoptosis, vol. 11, no. 8, pp. 1359-1369, 2006.

[168] L. Papucci, N. Schiavone, E. Witort et al., "Coenzyme $\mathrm{Q}_{10}$ prevents apoptosis by inhibiting mitochondrial depolarization independently of its free radical scavenging property," Journal of Biological Chemistry, vol. 278, no. 30, pp. 28220 28228, 2003.

[169] G. P. Littarru and L. Tiano, "Bioenergetic and antioxidant properties of coenzyme Q: recent developments," Molecular Biotechnology, vol. 37, no. 1, pp. 31-37, 2007.

[170] C. W. Shults, R. H. Haas, D. Passov, and M. F. Beal, "Coenzyme $\mathrm{Q}_{10}$ levels correlate with the activities of complexes I and II/III in mitochondria from Parkinsonian and nonparkinsonian subjects," Annals of Neurology, vol. 42, no. 2, pp. 261-264, 1997.

[171] A. K. Reeve, K. J. Krishnan, and D. Turnbull, "Mitochondrial DNA mutations in disease, aging, and neurodegeneration," Annals of the New York Academy of Sciences, vol. 1147, pp. 21-29, 2008.

[172] S. McCarthy, M. Somayajulu, M. Sikorska, H. BorowyBorowski, and S. Pandey, "Paraquat induces oxidative stress and neuronal cell death; neuroprotection by water-soluble Coenzyme Q," Toxicology and Applied Pharmacology, vol. 201, no. 1, pp. 21-31, 2004.

[173] Y. Moon, K. H. Lee, J. H. Park, D. Geum, and K. Kim, "Mitochondrial membrane depolarization and the selective death of dopaminergic neurons by rotenone: protective effect of coenzyme Q," Journal of Neurochemistry, vol. 93, no. 5, pp. 1199-1208, 2005.

[174] M. F. Beal, R. T. Matthews, A. Tieleman, and C. W. Shults, "Coenzyme $\mathrm{Q}_{10}$ attenuates the 1-methyl-4-phenyl1,2,3,6- tetrahydropyridine (MPTP) induced loss of striatal dopamine and dopaminergic axons in aged mice," Brain Research, vol. 783, no. 1, pp. 109-114, 1998.
[175] R. T. Matthews, L. Yang, S. Browne, M. Baik, and M. F. Beal, "Coenzyme $\mathrm{Q}_{10}$ administration increases brain mitochondrial concentrations and exerts neuroprotective effects," Proceedings of the National Academy of Sciences of the United States of America, vol. 95, no. 15, pp. 8892-8897, 1998.

[176] C. W. Shults, D. Oakes, K. Kieburtz et al., "Effects of coenzyme $\mathrm{Q}_{10}$ in early Parkinson disease: evidence of slowing of the functional decline," Archives of Neurology, vol. 59, no. 10, pp. 1541-1550, 2002.

[177] A. Storch, W. H. Jost, P. Vieregge et al., "Randomized, double-blind, placebo-controlled trial on symptomatic effects of coenzyme $\mathrm{Q}_{10}$ in Parkinson disease," Archives of Neurology, vol. 64, no. 7, pp. 938-944, 2007.

[178] M. F. Beal, "Effects of Coenzyme Q10 (CoQ) in Parkinson Disease (QE3)," 2010, http://clinicaltrials.gov/ct2/show/ NCT00740714?term=QE3+Parkinson\%27s\&rank=1.

[179] P. Klivenyi, R. J. Ferrante, R. T. Matthews et al., "Neuroprotective effects of creatine in a transgenic animal model of amyotrophic lateral sclerosis," Nature Medicine, vol. 5, no. 3, pp. 347-350, 1999.

[180] G. J. Brewer and T. W. Wallimann, "Protective effect of the energy precursor creatine against toxicity of glutamate and $\beta$-amyloid in rat hippocampal neurons," Journal of Neurochemistry, vol. 74, no. 5, pp. 1968-1978, 2000.

[181] R. J. Ferrante, O. A. Andreassen, B. G. Jenkins et al., "Neuroprotective effects of creatine in a transgenic Mouse model of Huntington's disease," Journal of Neuroscience, vol. 20, no. 12, pp. 4389-4397, 2000.

[182] R. H. Andres, A. W. Huber, U. Schlattner et al., "Effects of creatine treatment on the survival of dopaminergic neurons in cultured fetal ventral mesencephalic tissue," Neuroscience, vol. 133, no. 3, pp. 701-713, 2005.

[183] R. T. Matthews, R. J. Ferrante, P. Klivenyi et al., "Creatine and cyclocreatine attenuate MPTP neurotoxicity," Experimental Neurology, vol. 157, no. 1, pp. 142-149, 1999.

[184] P. Klivenyi, G. Gardian, N. Y. Calingasan, L. Yang, and M. F. Beal, "Additive neuroprotective effects of creatine and a cyclooxygenase 2 inhibitor against dopamine depletion in the 1-methyl-4-phenyl-1,2,3,6- tetrahydropyridine (MPTP) mouse model of Parkinson's disease," Journal of Molecular Neuroscience, vol. 21, no. 3, pp. 191-198, 2003.

[185] A. Bender, J. Beckers, I. Schneider et al., "Creatine improves health and survival of mice," Neurobiology of Aging, vol. 29, no. 9, pp. 1404-1411, 2008.

[186] A. Bender, W. Koch, M. Elstner et al., "Creatine supplementation in Parkinson disease: a placebo-controlled randomized pilot trial," Neurology, vol. 67, no. 7, pp. 1262-1264, 2006.

[187] J. Couzin, "Clinical research. Testing a novel strategy against Parkinson's disease," Science, vol. 315, no. 5820, p. 1778, 2007.

[188] L. Yang, N. Y. Calingasan, E. J. Wille et al., "Combination therapy with Coenzyme $\mathrm{Q}_{10}$ and creatine produces additive neuroprotective effects in models of Parkinson's and Huntington's Diseases," Journal of Neurochemistry, vol. 109, no. 5, pp. 1427-1439, 2009.

[189] K. Zhao, G. Luo, G. M. Zhao, P. W. Schiller, and H. H. Szeto, "Transcellular transport of a highly polar $3+$ net charge opioid tetrapeptide," Journal of Pharmacology and Experimental Therapeutics, vol. 304, no. 1, pp. 425-432, 2003.

[190] K. Zhao, G. M. Zhao, D. Wu et al., "Cell-permeable peptide antioxidants targeted to inner mitochondrial membrane inhibit mitochondrial swelling, oxidative cell death, and reperfusion injury," Journal of Biological Chemistry, vol. 279, no. 33, pp. 34682-34690, 2004. 
[191] H. H. Szeto, "Mitochondria-targeted cytoprotective peptides for ischemia-reperfusion injury," Antioxidants and Redox Signaling, vol. 10, no. 3, pp. 601-619, 2008.

[192] H. H. Szeto, "Development of mitochondria-targeted aromatic-cationic peptides for neurodegenerative diseases," Annals of the New York Academy of Sciences, vol. 1147, pp. 112-121, 2008.

[193] K. Zhao, G. Luo, S. Giannelli, and H. H. Szeto, "Mitochondria-targeted peptide prevents mitochondrial depolarization and apoptosis induced by tert-butyl hydroperoxide in neuronal cell lines," Biochemical Pharmacology, vol. 70, no. 12, pp. 1796-1806, 2005.

[194] L. Yang, K. Zhao, N. Y. Calingasan, G. Luo, H. H. Szeto, and M. F. Beal, "Mitochondria targeted peptides protect against 1-methyl-4-phenyl-1,2,3,6- tetrahydropyridine neurotoxicity," Antioxidants and Redox Signaling, vol. 11, no. 9, pp. 2095-2104, 2009.

[195] R. J. Nijveldt, E. van Nood, D. E. C. van Hoorn, P. G. Boelens, K. van Norren, and P. A. M. van Leeuwen, "Flavonoids: a review of probable mechanisms of action and potential applications," American Journal of Clinical Nutrition, vol. 74, no. 4, pp. 418-425, 2001.

[196] S. Guo, E. Bezard, and B. Zhao, "Protective effect of green tea polyphenols on the SH-SY5Y cells against 6-OHDA induced apoptosis through ROS-NO pathway," Free Radical Biology and Medicine, vol. 39, no. 5, pp. 682-695, 2005.

[197] Y. Levites, O. Weinreb, G. Maor, M. B. H. Youdim, and S. Mandel, "Green tea polyphenol (-)-epigallocatechin-3gallate prevents N-methyl-4-phenyl- 1,2,3,6-tetrahydropyridine-induced dopaminergic neurodegeneration," Journal of Neurochemistry, vol. 78, no. 5, pp. 1073-1082, 2001.

[198] JI. Y. Choi, C. S. Park, D. J. Kim et al., "Prevention of nitric oxide-mediated 1-methyl-4-phenyl-1,2,3,6tetrahydropyridine-induced Parkinson's disease in mice by tea phenolic epigallocatechin 3-gallate," NeuroToxicology, vol. 23, no. 3, pp. 367-374, 2002.

[199] G. Griffioen, H. Duhamel, N. van Damme et al., "A yeastbased model of $\alpha$-synucleinopathy identifies compounds with therapeutic potential," Biochimica et Biophysica ActaMolecular Basis of Disease, vol. 1762, no. 3, pp. 312-318, 2006.

[200] D. K. Y. Chan, J. Woo, S. C. Ho et al., "Genetic and environmental risk factors for Parkinson's disease in a Chinese population," Journal of Neurology Neurosurgery and Psychiatry, vol. 65, no. 5, pp. 781-784, 1998.

[201] P. Lorenz, S. Roychowdhury, M. Engelmann, G. Wolf, and T. F. W. Horn, "Oxyresveratrol and resveratrol are potent antioxidants and free radical scavengers: effect on nitrosative and oxidative stress derived from microglial cells," Nitric Oxide-Biology and Chemistry, vol. 9, no. 2, pp. 64-76, 2003.

[202] J. Chao, M. S. Yu, Y. S. Ho, M. Wang, and R. C. C. Chang, "Dietary oxyresveratrol prevents parkinsonian mimetic 6hydroxydopamine neurotoxicity," Free Radical Biology and Medicine, vol. 45, no. 7, pp. 1019-1026, 2008.

[203] S. A. Andrabi, M. G. Spina, P. Lorenz, U. Ebmeyer, G. Wolf, and T. F. W. Horn, "Oxyresveratrol (trans-2,3',4,5'tetrahydroxystilbene) is neuroprotective and inhibits the apoptotic cell death in transient cerebral ischemia," Brain Research, vol. 1017, no. 1-2, pp. 98-107, 2004.

[204] B. N. Ames, R. Cathcart, E. Schwiers, and P. Hochstein, "Uric acid provides an antioxidant defense in humans against oxidant- and radical-caused aging and cancer: a hypothesis," Proceedings of the National Academy of Sciences of the United States of America, vol. 78, no. 11, pp. 6858-6862, 1981.
[205] J. W. Davis, A. Grandinetti, C. I. Waslien, G. W. Ross, L. R. White, and D. M. Morens, "Observations on serum uric acid levels and the risk of idiopathic Parkinson's disease," American Journal of Epidemiology, vol. 144, no. 5, pp. 480484, 1996.

[206] T. Annanmaki, A. Muuronen, and K. Murros, "Low plasma uric acid level in Parkinson's disease," Movement Disorders, vol. 22, no. 8, pp. 1133-1137, 2007.

[207] M. G. Weisskopf, E. O'Reilly, H. Chen, M. A. Schwarzschild, and A. Ascherio, "Plasma urate and risk of Parkinson's disease," American Journal of Epidemiology, vol. 166, no. 5, pp. 561-567, 2007.

[208] A. Winquist, K. Steenland, and A. Shankar, "Higher serum uric acid associated with decreased Parkinson's disease prevalence in a large community-based survey," Movement Disorders, vol. 25, no. 7, pp. 932-936, 2010.

[209] R. F. Anderson and T. A. Harris, "Dopamine and uric acid act as antioxidants in the repair of DNA radicals: implications in Parkinson's disease," Free Radical Research, vol. 37, no. 10, pp. 1131-1136, 2003.

[210] W. Duan, B. Ladenheim, R. G. Cutler, I. I. Kruman III, J. L. Cadet, and M. P. Mattson, "Dietary folate deficiency and elevated homocysteine levels endanger dopaminergic neurons in models of Parkinson's disease," Journal of Neurochemistry, vol. 80, no. 1, pp. 101-110, 2002.

[211] S. Guerreiro, A. Ponceau, D. Toulorge et al., "Protection of midbrain dopaminergic neurons by the end-product of purine metabolism uric acid: potentiation by low-level depolarization," Journal of Neurochemistry, vol. 109, no. 4, pp. 1118-1128, 2009.

[212] T. A. Yacoubian and D. G. Standaert, "Targets for neuroprotection in Parkinson's disease," Biochimica et Biophysica Acta-Molecular Basis of Disease, vol. 1792, no. 7, pp. 676687, 2009.

[213] M. A. Schwarzschild, "Safety of Urate Elevation in Parkinson's Disease (SURE-PD)," November 2010, http://caltri. als.gov/ct2/show/NCT00833690?term=uric+acid\&rank=6.

[214] C. H. Lee, D. S. Hwang, H. G. Kim et al., "Protective effect of Cyperi Rhizoma against 6-hydroxydopamine-induced neuronal damage," Journal of Medicinal Food, vol. 13, no. 3, pp. 564-571, 2010.

[215] J. Lee, D. Son, P. Lee et al., "Protective effect of methanol extract of Uncaria rhynchophylla against excitotoxicity induced by N-methyl-D-aspartate in rat hippocampus," Journal Pharmacological Sciences, vol. 92, no. 1, pp. 70-73, 2003.

[216] B. Ma, C. F. Wu, J. Y. Yang, R. Wang, Y. Kano, and D. Yuan, "Three new alkaloids from the leaves of Uncaria rhynchophylla," Helvetica Chimica Acta, vol. 92, no. 8, pp. 1575-1585, 2009.

[217] J. S. Shim, H. G. Kim, M. S. Ju, J. G. Choi, S. Y. Jeong, and M. S. Oh, "Effects of the hook of Uncaria rhynchophylla on neurotoxicity in the 6-hydroxydopamine model of Parkinson's disease," Journal of Ethnopharmacology, vol. 126, no. 2, pp. 361-365, 2009.

[218] W. Koller, C. W. Olanow, R. Rodnitzky et al., "Effects of tocopherol and deprenyl on the progression of disability in early Parkinson's disease," New England Journal of Medicine, vol. 328, no. 3, pp. 176-183, 1993.

[219] B. J. Snow, F. L. Rolfe, M. M. Lockhart et al., "A doubleblind, placebo-controlled study to assess the mitochondriatargeted antioxidant MitoQ as a disease-modifying therapy in Parkinson's disease," Movement Disorders, vol. 25, no. 11, pp. 1670-1674, 2010. 


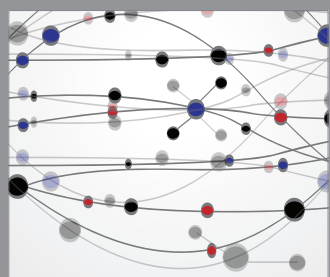

The Scientific World Journal
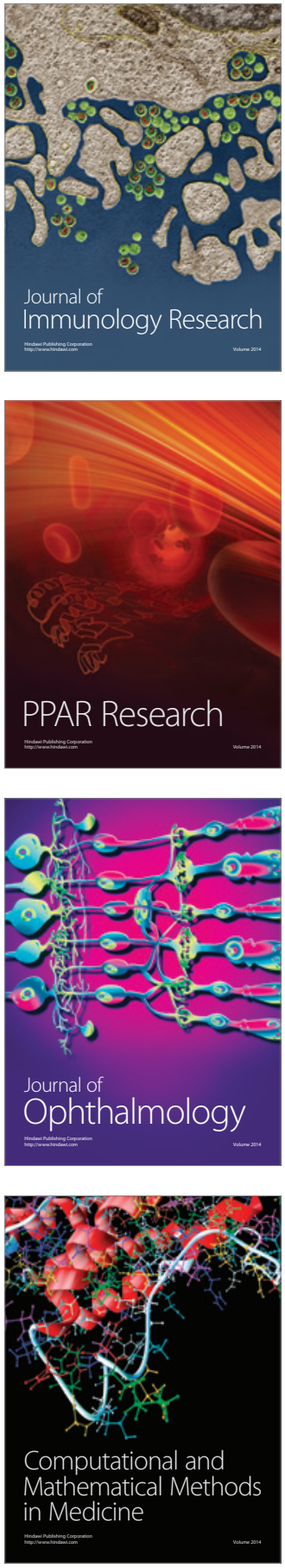

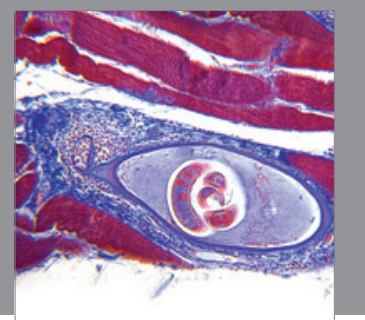

Gastroenterology

Research and Practice
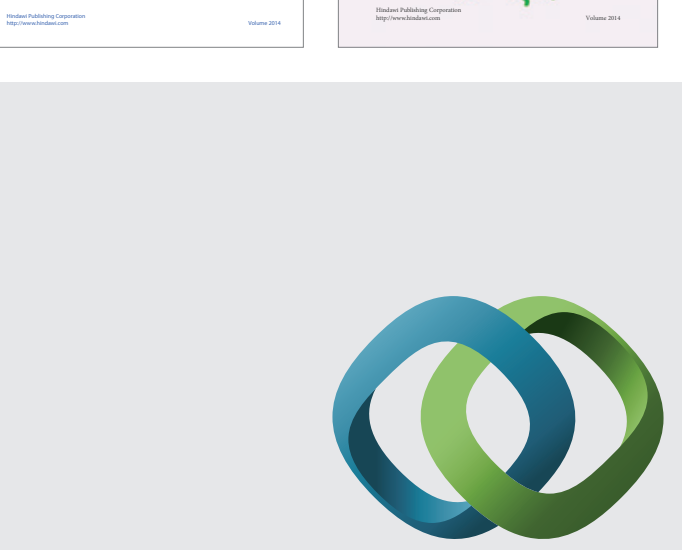

\section{Hindawi}

Submit your manuscripts at

http://www.hindawi.com
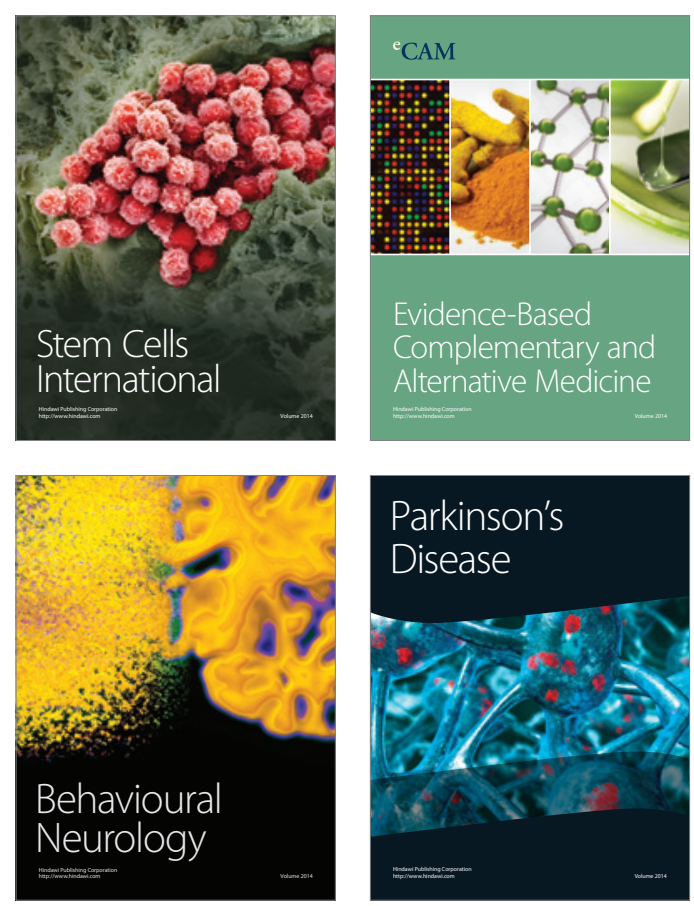

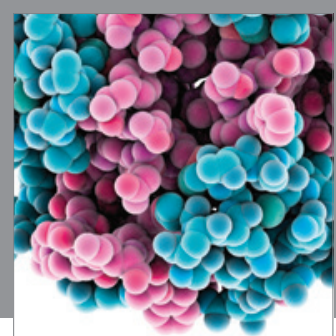

Journal of
Diabetes Research

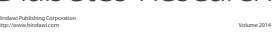

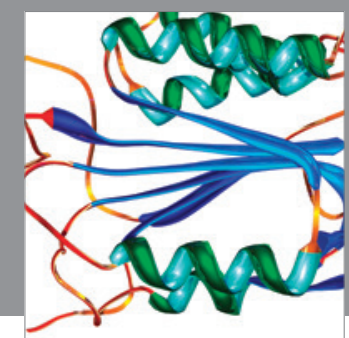

Disease Markers
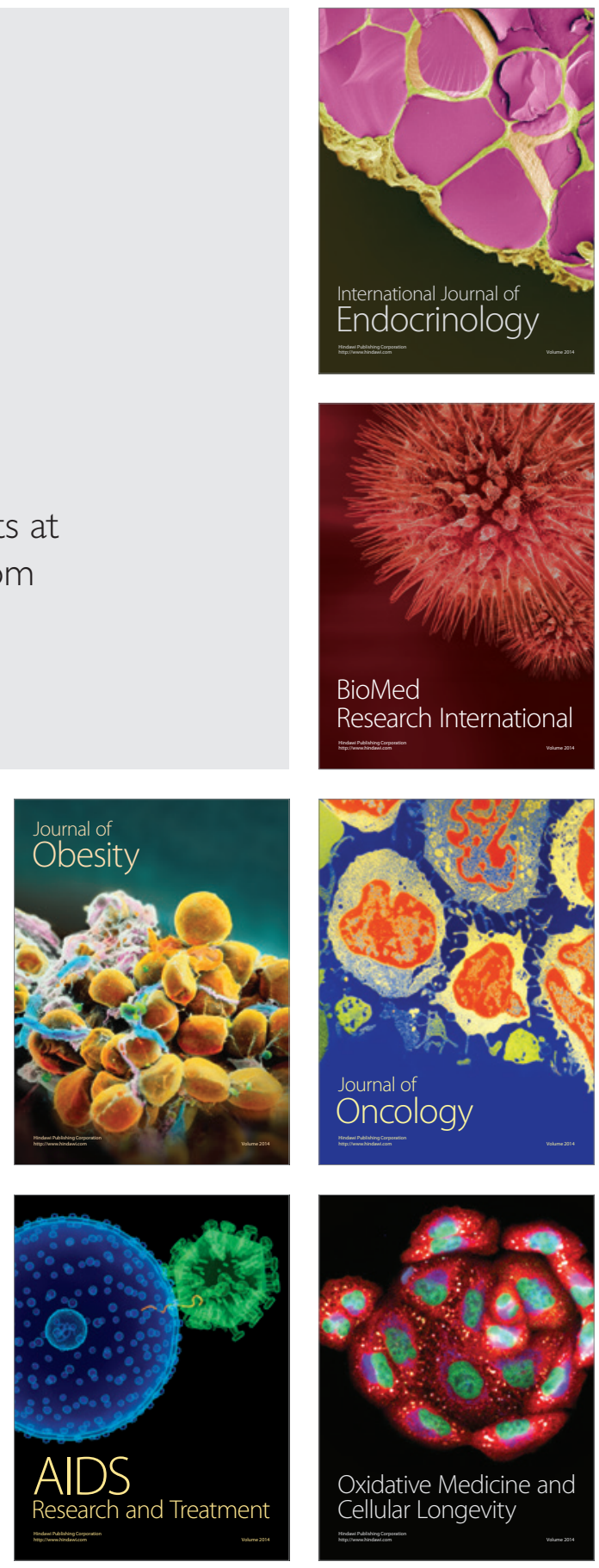